San Jose State University

SJSU ScholarWorks

Master's Theses

Master's Theses and Graduate Research

1991

\title{
The comparative effectiveness of ankle prophylactic devices in limiting inversion before and after vigorous exercise
}

Natalie Martin

San Jose State University

Follow this and additional works at: https://scholarworks.sjsu.edu/etd_theses

\section{Recommended Citation}

Martin, Natalie, "The comparative effectiveness of ankle prophylactic devices in limiting inversion before and after vigorous exercise" (1991). Master's Theses. 146.

DOI: https://doi.org/10.31979/etd.w5kb-wsd8

https://scholarworks.sjsu.edu/etd_theses/146

This Thesis is brought to you for free and open access by the Master's Theses and Graduate Research at SJSU ScholarWorks. It has been accepted for inclusion in Master's Theses by an authorized administrator of SJSU ScholarWorks. For more information, please contact scholarworks@sjsu.edu. 


\section{INFORMATION TO USERS}

This manuscript has been reproduced from the microfilm master. UMI films the text directly from the original or copy submitted. Thus, some thesis and dissertation copies are in typewriter face, while others may be from any type of computer printer.

The quality of this reproduction is dependent upon the quality of the copy submitted. Broken or indistinct print, colored or poor quality illustrations and photographs, print bleedthrough, substandard margins, and improper alignment can adversely affect reproduction.

In the unlikely event that the author did not send UMI a complete manuscript and there are missing pages, these will be noted. Also, if unauthorized copyright material had to be removed, a note will indicate the deletion.

Oversize materials (e.g., maps, drawings, charts) are reproduced by sectioning the original, beginning at the upper left-hand corner and continuing from left to right in equal sections with small overlaps. Each original is also photographed in one exposure and is included in reduced form at the back of the book.

Photographs included in the original manuscript have been reproduced xerographically in this copy. Higher quality 6" x 9" black and white photographic prints are available for any photographs or illustrations appearing in this copy for an additional charge. Contact UMI directly to order.

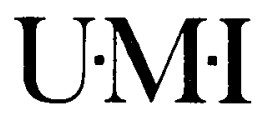

University Microfilms International

A Bell \& Howell Information Company 300 North Zeeb Road. Ann Arbor, MI 48106-1346 USA

$313 / 761-4700 \quad 800 / 521-0600$ 
Order Number 1344292

The comparative effectiveness of ankle prophylactic devices in limiting inversion before and after vigorous exercise

\author{
Martin, Natalie, M.A.
}

San Jose State University, 1991 
THE COMPARATIVE EFFECTIVENESS OF ANKLE PROPHYLACTIC DEVICES IN LIMITING INVERSION BEFORE AND AFTER VIGOROUS EXERCISE

\author{
A Thesis \\ Presented to \\ The Faculty of the Department of Human Performance \\ San Jose State University \\ In Partial Fulfillment \\ of the Requirements for the Degree \\ Master of Arts
}

By

Natalie Martin

May 1991 


\section{APPROVED FOR THE DEPARTMENT}

\section{OF HUMAN PERFORMANCE}

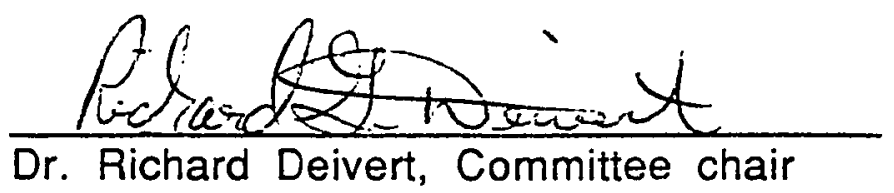

$\frac{\text { Nath Terk mo }}{\text { Dr. Martin Trieb, Committee member }}$

Q. Eidice ey

Dr. Bethanyl Shifflett, Committee member

APPROVED FOR THE UNIVERSITY

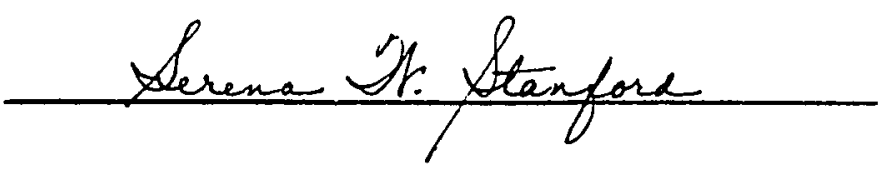




\section{ABSTRACT \\ COMPARATIVE EFFECTIVENESS OF ANKLE PROPHYLACTIC DEVICES IN LIMITING INVERSION BEFORE AND AFTER VIGOROUS EXERCISE \\ by Natalie Martin}

The prudence of prophylactic ankle taping continues to be questioned as recent clinical studies have revealed other forms of ankle stabilization to be as or more effective in injury prevention. The purpose of this study was to compare the effectiveness of three modes of ankle prophylaxis (closed basketweave adhesive taping, lace-up brace, and semirigid orthosis) with a control condition (no support) in limiting ankle inversion under dynamic loads imposed by repetitive walking ( $4 \mathrm{mph}$ ) and running ( $9 \mathrm{mph}$ ) on a treadmill tilted laterally. Ten subjects participated in four separate, randomly assigned testing sessions in which they were videotaped during treadmill walking and running before and after 20 minutes of vigorous exercise. At both $4 \mathrm{mph}$ and $9 \mathrm{mph}$, the semirigid orthosis provided the most inversion restraint, followed by the lace-up brace, closed basketweave taping, and the control condition. It was concluded that the semirigid orthosis and lace-up brace were more effective in limiting dynamic ankle inversion than was prophylactic ankle taping, both before and after exercise. 


\section{Ackowledgements}

I would like to acknowledge and extend my appreciation to the following individuals:

Dr. Richard Deivert, the chairman of my committee, for stepping in when his guidance was needed and for his continuous help in completing this study.

Dr. Martin Trieb, for his support and his valuable suggestions which have helped complete this thesis.

Dr. Bethany Shifflett, for her time, knowledge, and suggestions especially in the area of data analysis and interpretation.

Dr. Rod Harter, for all the work he put into guiding this effort even after he was no longer "officially" involved. Without his support this study would never have been started, much less completed.

Tom Kelley, Swede-O-Universal, for providing the lace-up ankle stabilizers.

Jim Johnson, Air-Cast, for providing the semirigid orthoses.

This thesis is dedicated to my parents, without whose love, support, and belief in my abilities this thesis would not have been possible. 


\section{TABLE OF CONTENTS}

\begin{tabular}{|c|c|c|c|c|c|c|c|c|c|c|c|c|c|c|}
\hline ABSTRACT . . & . . . & . & & . & . & . & & • & & & & & & \\
\hline Acknowledgements & . & . & 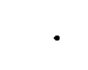 & . & . & . & • & - & . & & & & & \\
\hline Table of Contents . & . . & . & & . & . & . & & . & • & . & & & & \\
\hline List of Tables & . . . & . & . & $\cdot$ & . & . & • & . & . & . & & & & \\
\hline List of Figures & $\cdot \cdot \cdot$ & • & . & . & $\cdot$ & . & • & . & · & & & & & \\
\hline INTRODUCTION & - & . & $\cdot$ & . & . & . & . & . & • & . & & & & \\
\hline CHAPTER 1 & . & . & . & . & $\cdot$ & . & . & . & & & & & & \\
\hline Statement of th & he Proble & em. & & . & . & $\cdot$ & . & . & & & & & & \\
\hline Statement of th & he Purpos & ose . & . & . & . & . & . & . & . & & & . & & \\
\hline Research Hypc & othesis . & . . & $\cdot \cdot$ & $\cdot$ & - & . & . & . & $\cdot$ & & & & & \\
\hline Definition of $T$ & Cerms. & · $\cdot$ & • & $\cdot$ & $\cdot$ & $\cdot$ & - & $\cdot$ & . & 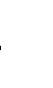 & 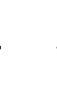 & & & \\
\hline Delimitations & . & $\cdot$ & - & . & $\cdot$ & - & . & . & - & . & 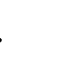 & • & & \\
\hline Limitations & $\cdot \cdot \cdot$ & . . & .. & . & $\cdot$ & . & . & . & · & 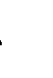 & 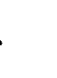 & & & \\
\hline Assumptions & . & & & . & . & . & - & . & & & & • & & \\
\hline
\end{tabular}

REVIEW OF THE LITERATURE $\quad$. . . . . . . . . . . . . . . 7

CHAPTER 2 . . . . . . . . . . . . . . . . . 7

Introduction . . . . . . . . . . . . . . . . . 7

Anatomy of the Ankle . . . . . . . . . . . . . . . . 8

Mechanisms of Ankle Injury . . . . . . . . . . . . . . . . . 9

Inversion Ankle Injury $\quad \cdot \quad$.

Eversion Ankle Injury

External Ankle Support . . . . . . . . . . . . . . 13

Prophylactic Ankle Taping . . . . . . . . . . . . 13 
Ankle Stabilizers . . . . . . . . . . . . . . . 18

Semirigid Orthoses . . . . . . . . . . . . . 20

Summary . . . . . . . . . . . . . . . . . 21

METHODS . . . . . . . . . . . . . . . . . 24

CHAPTER 3 . . . . . . . . . . . . . . . . . 24

Introduction . . . . . . . . . . . . . . . . . 24

Subjects . . . . . . . . . . . . . . . . . . . 24

Experimental Protocol . . . . . . . . . . . . . . 25

Instrumentation . . . . . . . . . . . . . . . . 30

Ankle Prophylactic Devices . . . . . . . . . . . 31

Closed Basketweave Ankle Taping . . . . . . . . . 31

Lace-Up Ankle Stabilizer . . . . . . . . . . . . . . 33

Semirigid Orthotic Device . . . . . . . . . . . 35

Data Analysis . . . . . . . . . . . . . . . . . 35

Summary . . . . . . . . . . . . . . . . . . . 37

RESULTS AND DISCUSSION . . . . . . . . . . . . . . . . . 39

CHAPTER 4 . . . . . . . . . . . . . . . . . . . 39

Introduction . . . . . . . . . . . . . . . . . 39

Description of Subjects . . . . . . . . . . . . . . . . . 39

Active Inversion Measurements . . . . . . . . . . . . 41

Average Maximum Inversion Angle Measurements . . . . . . . . 41

Subjective Rankings . . . . . . . . . . . . . . . . 42

Summary . . . . . . . . . . . . . . . . . . . 42

Discussion . . . . . . . . . . . . . . . . . . . . 43 
SUMMARY, CONCLUSIONS, AND RECOMMENDATIONS FOR

FUTURE STUDY . . . . . . . . . . . . . . . . . 48

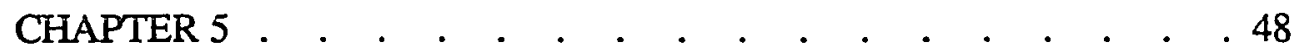

Introduction . . . . . . . . . . . . . . . . . 48

Summary . . . . . . . . . . . . . . . . . 48

Conclusions . . . . . . . . . . . . . . . . . . 51

Recommendations for Future Research . . . . . . . . . . 52

REFERENCES . . . . . . . . . . . . . . . . . 54

APPENDICES . . . . . . . . . . . . . . . . . . . 60

A - Consent Form . . . . . . . . . . . . . . . . . 60

B - Ratings of Prophylactic Devices . . . . . . . . . . 62

C-Data Recording Sheet . . . . . . . . . . . . . 64

D- Raw Data Scores . . . . . . . . . . . . . . . 65 


\section{LIST OF TABLES}

page

Table 1 Subject and group characteristics . . . . . . . . . 40

Table 2 Average maximum inversion angle measurements . . . . 46 


\section{LIST OF FIGURES}

page

Figure 1 Subtalar and ankle joint anatomy . . . . . . . 10

Figure 2 Mechanisms of ankle injury . . . . . . . . . 11

Figure 3 Gibney closed basketweave taping technique . . . . 15

Figure 4 Condition order . . . . . . . . . . . . . . . 26

Figure 5 Anatomical reference points . . . . . . . . . . 28

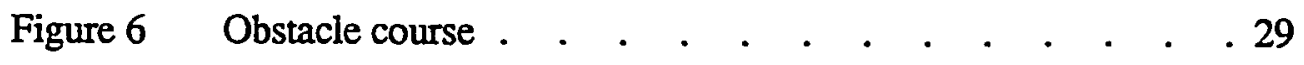

Figure 7 Test area view from video camera . . . . . . . . . 32

Figure 8 Swede-O-Universal@ lace-up ankle stabilizer . . . . . 34

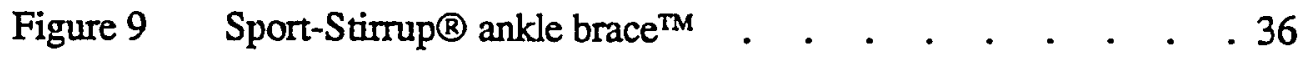




\section{CHAPTER 1}

\section{INTRODUCTION}

External support for prevention of athletic injury to the ankle joint has traditionally been confined to adhesive taping techniques such as the Gibney boot or closed basketweave procedures. The nature of the support provided by these adhesive taping procedures has been investigated by numerous authors during the past three decades (Abdenour, Saville, White, \& Abdenour, 1979; Emerick, 1979; Fumich, Ellison, Guerin, \& Grace, 1981; Garrick, 1977; Garrick \& Requa, 1973; Gross, Bradshaw, Ventry, \& Weller, 1987; Hughes \& Stetts, 1983; Laughman, Carr, Chao, Youndus, \& Sim, 1980; Malina, Plagnez, \& Rarick, 1963; McIntyre, Smith, \& Denniston, 1983; Metcalf \& Denegar, 1983; Rarick, Bigley, Karst, and Malina, 1962; Seitz \& Goldfuss, 1984; Simon, 1969).

Recently, several clinical studies have evaluated the use of lace-up ankle stabilizers as an alternative, possibly more effective method of protecting the ankle from excessive inversion (Bunch, Bednarski, Holland, \& Macinanti, 1985; Rovere, Clark, Yates, \& Burley, 1988).

Additionally, semirigid ankle orthotic devices have been used to protect an injured ankle from further trauma during the healing phase (Bergfeld, Cox, Drez, Raemy, \& Weiker, 1986). Kimura, Nawoczenski, Epler, and Owen (1987) suggested a different role for the Air-Stirrup ${ }^{\circledR}$ as a prophylactic ankle brace. Unlike ankle taping and lace-up ankle braces, semirigid orthoses primarily limit inversion and eversion and not plantarflexion and dorsiflexion (Burdett, Borello-France, Blatchly, \& Potter, 1988; Hoshowski, 1988; Kimura et al., 1987; Raemy \& Jakob, 1983; Stover, 1979; Stover, 1980; Stover \& York, 
1979; Stover, 1986; Stover \& DeBald, 1986). Semirigid orthoses may also retain their initial level of range of motion restriction as the Velcroß straps do not loosen like the laces of the ankle stabilizers.

Historically, experimental results have been controversial with regard to the effectiveness of ankle taping. Laughman et al. (1980) reported ankle taping to be effective at limiting the extremes of motion associated with inversion ankle sprains. However, Rarick et al. (1962) reported that tape lost 40 percent of its initial ankle support after 10 minutes of exercise. Rovere et al. (1988) noted that lace-up ankle stabilizers have the potential to maintain their protective characteristics throughout an exercise bout if the athlete tightens the laces as they loosen during activity. Kimura et al. (1987) found a semirigid orthosis to be effective in preventing static inversion, but suggested further research into the effectiveness of the orthosis in actual sport and movement participation situations.

To date, lace-up ankle stabilizer effectiveness is not well-documented as this form of ankle prophylaxis has received less experimental attention compared to ankle taping techniques. Bunch et al. (1985) compared the effectiveness of in vitro ankle taping and reusable lace-up ankle braces and found that tape initially offered greater support. After an average of 305 inversion cycles on a mechanical ankle model manufactured for the study, taping provided no better support than did the ankle braces, suggesting similar levels of support were provided by these two restraining devices (Bunch et al., 1985).

Rovere et al. (1988) estimated the cost of mandatory ankle taping to be more than $\$ 400.00$ per athlete per season while the lace-up ankle stabilizers used cost approximately $\$ 64.00$ per person (two pairs per athlete per season). Existing data suggest equivocal support provided by ankle taping and ankle bracing. The greater cost of ankle taping compared to ankle stabilizers may be a determining factor in the selection of the type of 
prophylactic and postinjury ankle support used, particularly in schools with limited budgets and resources.

\section{Statement of the Problem}

In spite of numerous studies which document the limitations of its effectiveness, athletic tape continues to be the most commonly applied external ankle prophylactic device used in athletics (Abdenour et al.,1979; Emerick, 1979; Fumich et al., 1981; Garrick, 1977; Garrick \& Requa, 1973; Gross et al., 1987; Hughes \& Stetts, 1983; Laughman et al., 1980; Malina et al., 1963; McIntyre et al., 1983; Metcalf \& Denegar, 1983; Seitz \& Goldfuss, 1984; Simon, 1969). Recently, lace-up ankle stabilizers have been reported as an equivocal method of providing this protection (Bunch et al., 1985; Rovere et al., 1988). The efficacy of semirigid orthoses in ankle injury prophylaxis has yet to be determined (Kimura et al., 1987).

\section{Statement of the Purpose}

The purpose of this study was to measure and compare the effectiveness of closed basketweave inversion ankle taping, a lace-up ankle stabilizer (Swede-O-Universal, North Branch, Minnesota), and a semirigid ankle orthotic device (Sport-Stimup ${ }^{\circledR}$ ankle brace, Summit, New Jersey), in limiting ankle inversion under dynamic loads imposed by repetitive walking and running on a treadmill tilted laterally (5\% road grade; 6.5 degrees) before and after a 20-minute exercise bout.

\section{Research Hypothesis}

Closed basketweave athletic taping, the lace-up ankle stabilizer, and the semirigid orthosis will be equally effective in preventing pathologic inversion. 


\section{Definition of Terms}

The following terms will be used in this study and are defined for classification.

Inversion. According to Daniels and Worthington (1986) the normal range of foot inversion is approximately $30-40$ degrees; therefore, more than 40 degrees of ankle inversion will be considered excessive when compared to the opposite side.

Normal Foot. Hlavac (1977) defines a normal foot as one in which the heel bone is in line with the leg and perpendicular to the supporting surface and the forefoot is perpendicular to the rearfoot and parallel to the supporting surface. Additionally, a normal foot possesses a normal range of motion at the ankle joint , there is good tone and balanced strength of the leg muscles, and during weight bearing, the contact of the foot should be distributed between the heel and the ball of the foot (Booher \& Thibodeau, 1988;

Cavinagh, Rogers, \& Iiboshi, 1987).

Talar Tilt. Ligament test for the calcaneofibular and calcaneotibial ligaments. The talus is tilted from side-to-side into inversion and eversion. An inversion talar tilt of greater than 15 degrees indicates significant ligament laxity (Perlman et al., 1987). A talar tilt of 10 degrees or less is considered normal when compared to the opposite side (Cox et al., 1986). However, the only truly quantifiable method of determining talar tilt is through the use of roentgenograms.

Anterior Drawer Test. Ligament test in which the calcaneus and talus are pulled anteriorly while stabilizing the tibia with the ankle in neutral position (Arnheim, 1989; Cox et al., 1986; Hoppenfeld, 1976; Magee, 1987; Roy \& Irvin, 1983). Ligament laxity of 3 mm or greater when compared to the noninvolved ankle indicates a significant sprain of the anterior talofibular ligament (Cox et al., 1986).

Heel Strike, For the purpose of digitizing, heel strike is the first video frame in which the right heel and/or foot comes in contact with the treadmill surface. 
Toe Off. For the purpose of digitizing, toe off is the last frame in which the right leg is the primary weight bearing limb.

Certified Athletic Trainer (A.T.C.). An individual who has completed a program of formal academic preparation and supervised practical experience in accordance with guidelines approved by the National Athletic Trainers' Association (NATA). This individual then must pass a two-part oral and written certification examination which tests competency in both practical and theoretical aspects of health care in an athletic environment.

\section{Delimitations}

The following delimitations in the interpretation of data and generalization of results are acknowledged:

1. The subjects participating in the study denied prior history of injury to either ankle and met the following criteria: (a) passive inversion of 30 degrees or less, and (b) a negative anterior drawer sign ( $2 \mathrm{~mm}$ or less in neutral position in comparison to the opposite ankle) (Cox, Inniss, Lee, \& Woodward, 1986).

\section{Limitations}

The following are limitations of the current study:

1. While the same certified athletic trainer applied the closed basketweave adhesive taping procedure to every subject, the consistency in the tape tension may have varied from subject to subject, and from experimental session to session.

2. Each subject may have perceived the tightness of the lace-up ankle stabilizer or semirigid orthosis differently, and thus the same levels of support may not be present across subjects. 
3. A video field framing rate of $60 \mathrm{~Hz}$ will be used to determine the maximum angles of inversion and dorsiflexion.

\section{Assumptions}

It is assumed that:

1. The subjects will exert a maximal effort in the obstacle course, and while walking and running on the treadmill.

2. Subjects will provide correct and accurate information regarding ankle injury history.

\section{Summary}

Based strongly upon tradition and empirical claims, adhesive ankle taping remains the primary method of providing athletes with prophylactic ankle support. Recently, the use of lace-up ankle stabilizers has been proposed as an alternative to prophylactic ankle taping. Semirigid orthotic devices, originally designed to protect an injured ankle as it healed, have also been suggested as an alternative to both adhesive taping or lace-up types of ankle stabilization for the prevention of pathologic ankle motion.

Experimental results are conflicting with regard to the effectiveness of these ankle supports. While some studies found taping to be effective compared to controls, others have reported extreme limitations to that support. Recent in vitro as well as epidemiologic studies have cited lace-up ankle stabilizers as devices that provide significant, prolonged ankle protection. The semirigid orthotic device may provide equal or greater inversion ankle support when compared to adhesive ankle taping due to its semirigid structure and Velcro® fastening system, which limits loosening during activity. 


\section{CHAPTER 2}

\section{REVIEW OF THE LITERATURE}

\section{Introduction}

On a daily basis many high school, college, and professional athletes have their ankles taped for the prevention of injury. The annual costs of this practice has been estimated to be in the hundreds of thousands of dollars and millions of hours of labor are required to apply the tape (Garrick, 1977). In spite of this time committment, ankle injuries continue to occur and constitute a significant threat to the athletes' continued participation (Emerick, 1979; Garrick, 1977; Hughes \& Stetts, 1983; Laughman et al., 1980; McCluskey, Blackburn, \& Lewis, 1976).

The thigh, knee, and ankle are the three most common sites of injury in competitive athletics (Garrick, 1977). The ankle is unique in that the vast majority (85 percent) of injuries are sprains, and an equally high percentage of the sprains involve the lateral structures (Garrick, 1977). Garrick (1977) estimated that one ankle injury occurs for every 17 participants per season at the high school level.

This chapter will focus on the anatomical structure of the ankle, the mechanisms of ankle injury, the underlying theories and research investigations regarding the use of external ankle supports, specifically, closed basketweave adhesive athletic taping, lace-up ankle stabilizers, and semirigid orthoses, in relation to their effectiveness in preventing ankle injury. 


\section{Anatomy of the Ankle}

The ankle (tibiotalar) joint is a uniaxial, modified hinged, synovial joint (Magee, 1987). This joint is formed by the articulation between the tibia and fibula of the lower leg and the talus of the foot (Magee, 1987). The talus is wider anteriorly providing more stability in dorsiflexion because the talus becomes wedged between the malleoli, creating a "mortise effect" (Magee, 1987). The distal end of the tibia forms the medial malleolus (Magee, 1987). The lateral malleolus arises from the fibula and extends approximately one-half inch distal to the medial malleolus (Magee, 1987). The ankle joint allows only plantarflexion and dorsiflexion, but the subtalar joint allows inversion and eversion (Arnheim, 1989; Magee, 1987).

The subtalar joint is formed by the articulation between the talus and the calcaneus (Arnheim, 1989; Booher \& Thibodeau, 1989). This is a diarthrotic, gliding type of joint with a capsule and a synovial membrane (Arnheim, 1989; Booher \& Thibodeau, 1989). Inversion and eversion of the foot take place at both the subtalar and talocalcaneo-navicular joints (Booher \& Thibodeau, 1989). A limited range of inversion and eversion are necessary in athletics as these motions enable the body to move laterally over the foot while the foot remains fixed (Booher \& Thibodeau, 1989). Ankle sprains occur because of extreme motion at the subtalar joint, not the ankle joint (see Figure 1).

The medial aspect of the ankle is supported by the deltoid ligament, which consists of the tibionavicular, posterior tibiotalar, tibiocalcaneal, and anterior tibiotalar ligaments (Magee, 1987). The relative shortness of the medial malleolus and natural tendency for the ankle to invert predisposes the ankle to lateral sprains (Garrick, 1977). Lateral sprains account for approximately 85 percent of all ligamentous injuries to the ankle (Arnheim, 1989; Hughes \& Stetts, 1983; O'Donoghue, 1984). 
Figure 1. Subtalar and ankle joint anatomy.
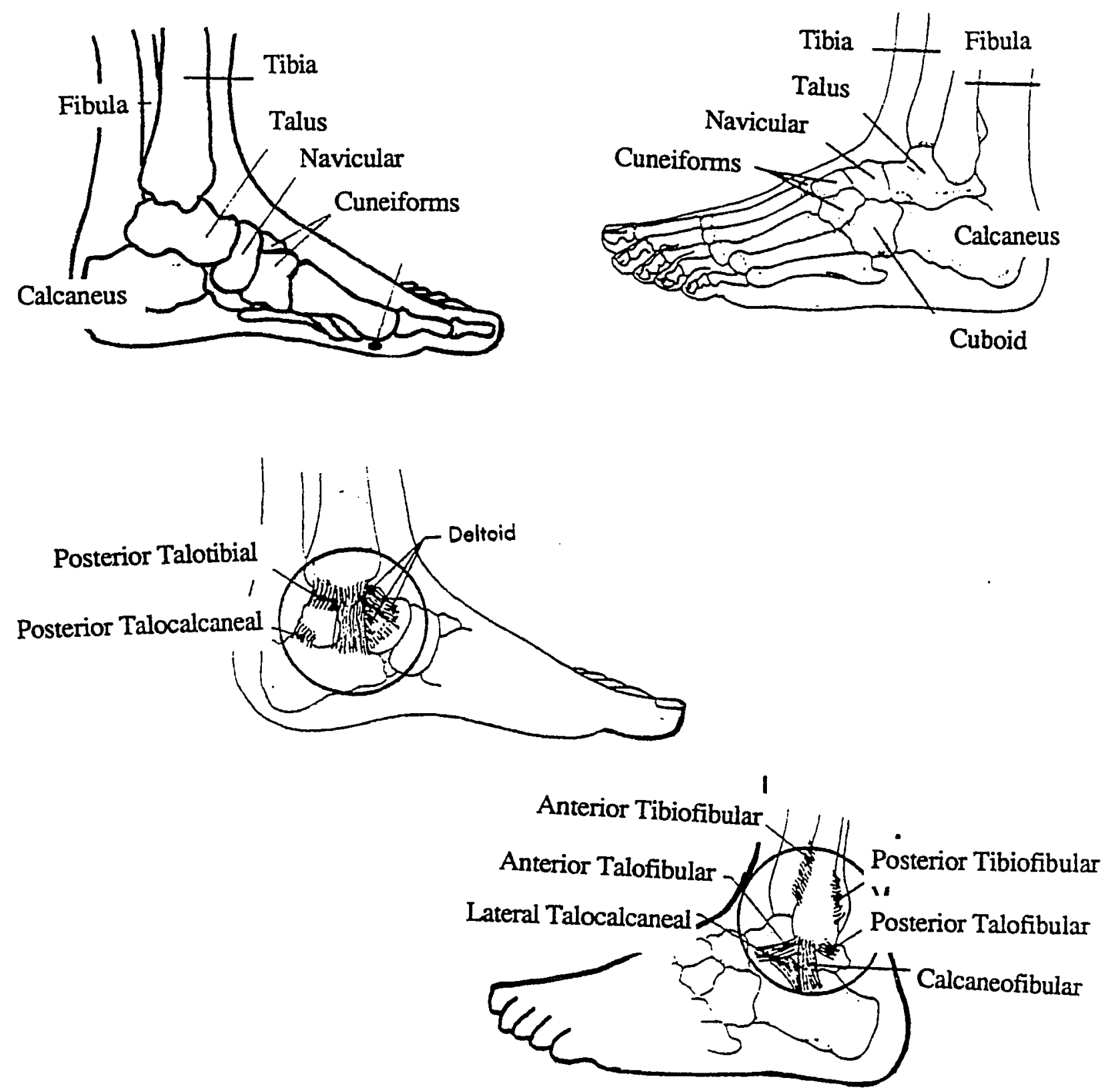

Taken from: Arnheim, D.D. (1989). Modern principles of athletic training (7th ed.), St.

Louis: Mirror/Mosby. 
During forceful inversion the medial malleolus may become a fulcrum, causing further inversion injury (Booher \& Thibodeau, 1989). The lateral aspect of the ankle joint is composed of the anterior talofibular, calcaneofibular, and posterior talofibular ligaments (Magee, 1987). The mechanism by which these three ligaments are injured is primarily inversion, with combinations of plantarflexion, rotation, and inversion also responsible (Moseley, 1965; Perlman et al., 1987) (see Figure 2).

The distal tibiofibular syndesmosis is supported by the anterior tibiofibular, posterior tibiofibular, and inferior transverse ligaments as well as the interosseous membrane (Magee, 1987). The tibiofibular ligaments are frequently damaged in rotational-type and eversion sprains of the ankle (Roy \& Irvin, 1983).

The weakest aspect of the ankle is its muscular arrangement (Arnheim, 1989). The long tendons of the muscles of the lower leg cross all sides of the ankle, creating excellent muscle leverage but poor stabilization (Amheim, 1989).

\section{Mechanisms of Ankle Injury}

The most common ankle injury is a lateral sprain involving the anterior talofibular ligament. Numerous combinations of movement can result in stress on the three major lateral ligaments (Arnheim, 1989; Metcalf \& Denegar, 1983; Roy \& Irvin, 1983). Less frequently, the medial ligaments are damaged (Arnheim, 1989; Roy \& Irvin, 1983). Medial sprains are typically more severe and involve a longer period of rehabilitation because the interosseous membrane between the tibia and fibula is typically ruptured in addition to the medial ligament complex (Arnheim, 1989; Cox et al., 1986; Roy \& Irvin, 1983). The complete rupture of the anterior tibiofibular ligament and the interosseous membrane results in a disruption of the mortise causing further instability of the ankle (Arnheim, 1989; Cox et al., 1986; Roy \& Irvin, 1983). A dorsiflexion injury may also 
Figure 2. Mechanisms of ankle injury.
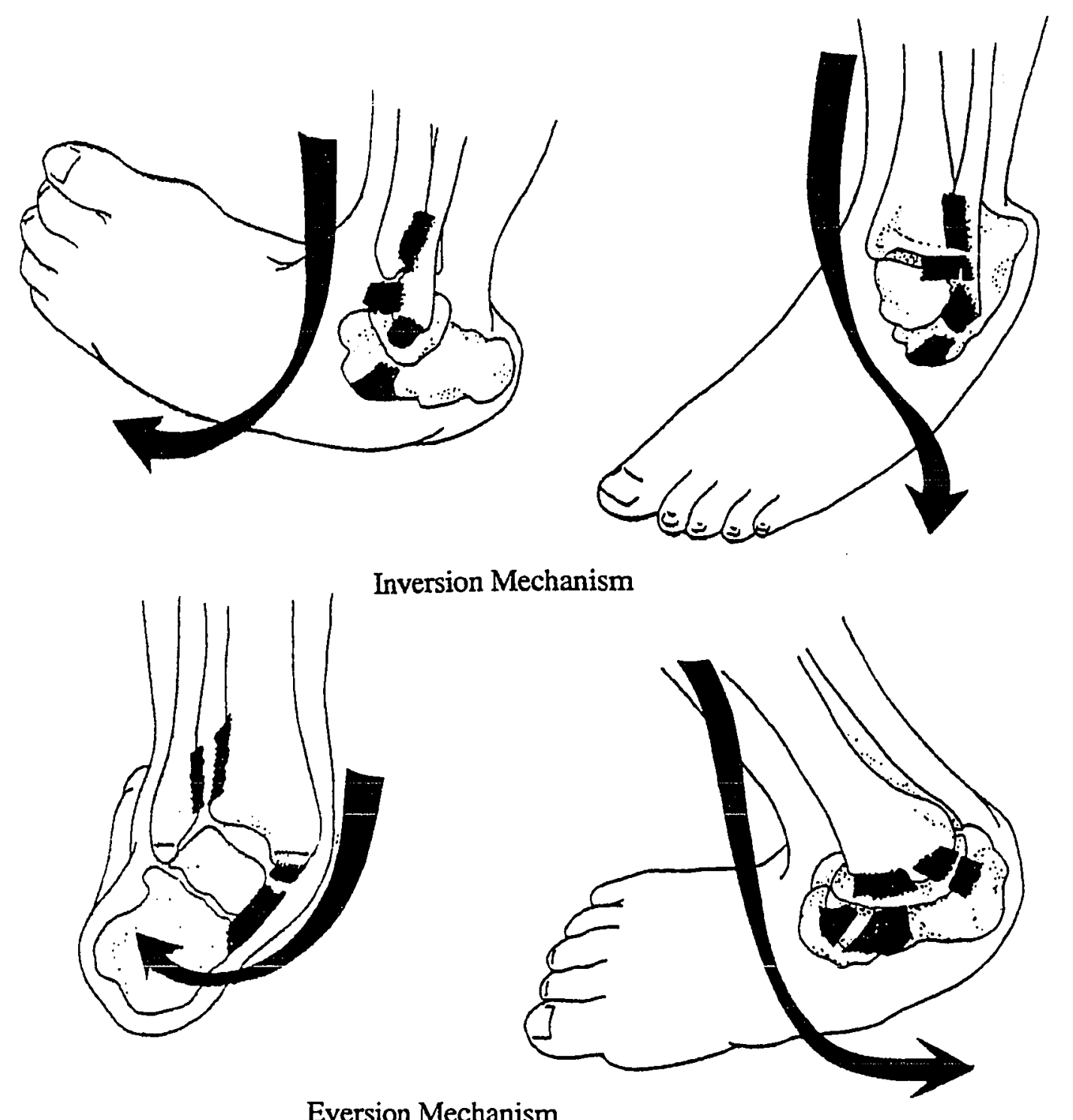

Taken from: Arnheim, D.D. (1989). Modern principles of athletic training, (7th ed.), St.

Louis: Mirror/Mosby. 
occur which would cause a rupture of the anterior and/or posterior tibiofibular ligaments leading to a widening of the ankle mortise and an unstable ankle (Arnheim, 1989).

Inversion Ankle Injury. Inversion sprains most commonly involve the combination of ankle plantarflexion, subtalar inversion, and internal rotation of the tibia (Metcalf \& Denegar, 1983; Roy \& Irvin, 1983). The typical inversion mechanism may include pure inversion, or more frequently inversion combined with plantarflexion (Arnheim, 1989; Garrick, 1977; Roy \& Irvin, 1983). The injury can be dynamic, such as a poorly-executed cutting maneuver enhanced by inadvertent foot fixation. It may also result from landing on an irregular playing surface; for example, a rutted playing field or, more commonly, landing on another player's foot (Arnheim, 1989; Garrick, 1977; Roy \& Irvin, 1983).

Eversion Ankle Injury. Eversion sprains occur infrequently due to the bony anatomy of the ankle joint and the strength of the deltoid ligament (Roy \& Irvin, 1983). An eversion sprain of the second degree (difference of between 5-10 mm ligament laxity in comparison to the uninjured ankle) or greater severity can produce significant joint instability (Amheim, 1989; Roy \& Irvin, 1983). The deltoid ligament is involved in supporting the medial longitudinal arch, and a sprain can also cause weakness in this area (Arnheim, 1989). With an eversion force, the talus is driven forcibly against the lateral malleolus, and severe pressure is applied to the malleolus before overstress of the short medial collateral ligament occurs. As the force continues, the medial collateral ligament gives way or the lateral malleolus fractures (O'Donoghue, 1984; Rasch, 1989). The common mechanism of injury occurs in football when the foot is firmly planted on the ground and another player falls against the lower leg, or in soccer when the foot strikes another player or the ground instead of the ball (Amheim, 1989; Cox, 1982; Roy \& Irvin, 1983). Generally, the more 
forceful the external rotation, the more anatomical structures traumatized and the more severe the injury (Amheim, 1989; Moseley, 1965; Roy \& Irvin, 1983).

\section{External Ankle Support}

External ankle support increases stability by reinforcing the ligamentous structures of the ankle joint and restricting extreme motion (Hughes \& Stetts, 1983; Libera, 1972). The primary objective of any external support is to prevent inversion sprains through restriction of available inversion and plantarflexion (Libera, 1972). By restricting active inversion, the motion available to the athlete at the extremes of inversion will also be limited (Hughes \& Stetts, 1983). External constraints should also support the joint during activity and prevent hypermobility of the ankle without severely inhibiting normal biomechanics (Libera, 1972).

Prophylactic Ankle Taping. Adhesive taping to prevent injuries to healthy ankles during athletic participation dates back to the early days (Circa 1890's) of intercollegiate football (Emerick, 1979). Athletic trainers, coaches, and team physicians have used adhesive strapping to limit the extremes of ankle motion available to the athlete (Hughes \& Stetts, 1983).

The Gibney closed basketweave taping technique (see Figure 3) has been commonly used in research studies evaluating the effectiveness of athletic adhesive taping (Bunch et al.,1985; Emerick, 1979; Fumich et al., 1981; Garrick \& Requa, 1973; Gross et al., 1987; Hamill et al., 1988; Laughman et al., 1980; Libera, 1972; Malina et al., 1963; McCluskey et al., 1976; McIntyre et al., 1983; Myburgh, Vaughn, \& Isaacs, 1984; Rovere et al., 1988; Seitz \& Goldfuss, 1984; Vaes, DeBoeck, Handelberg, \& Opdecum, 1985; Walsh \& Blackburn, 1977; Walters, Elledge, Tolson, \& Pankey, 1988). This particular technique 
Figure 3. Gibney closed basketweave taping technique.

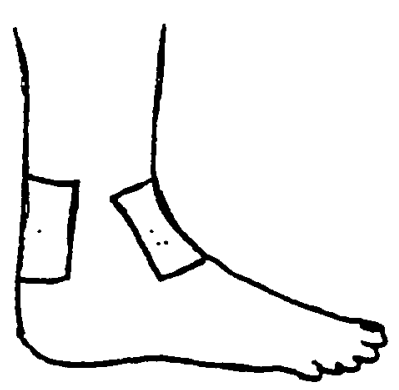

Heel and Lace Pads

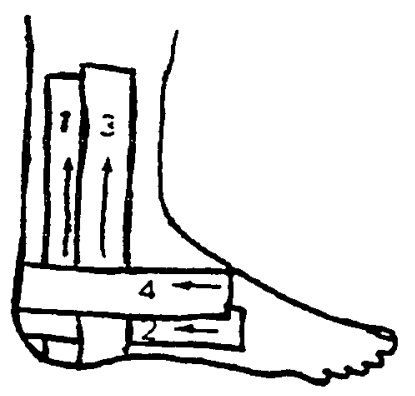

Basketweave

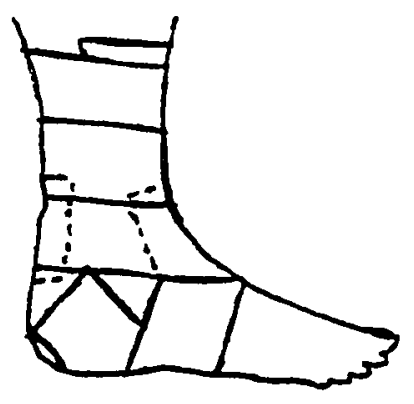

Underwrap

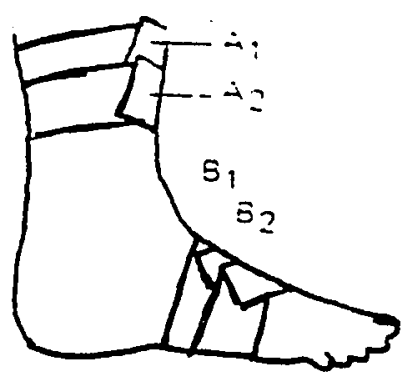

Anchor Strips

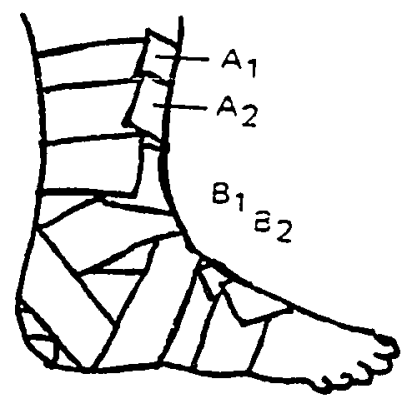

Finished Gibney Closed Basketweave

Taken from: Roy, S., \& Irvin, R. (1983). Sportsmedicine: Prevention, evaluation, management, and rehabilitation, Englewood Cliffs, NJ: Prentice-Hall. 
offers tape support and is primarily used to protect newly-sprained or chronically sprained ankles (Arnheim, 1989). Several authors have reported that a closed basketweave technique provided the best support to the ankle when compared with other taping methods (Glick, Gordon, \& Nishimoto, 1976; Libera, 1972; Malina, Plagnez \& Rarick, 1963; Rarick et al., 1962).

The effectiveness of athletic adhesive taping procedures is dependent on the foot maintaining the ankle's neutral position to reduce the varus or valgus moments occurring about the subtalar axis and thereby reducing ligamentous stress (Laughman et al., 1980). The effectiveness is more dependent upon the tape's tensile strength than its adhesive properties (Laughman et al., 1980). Correctly applied athletic tape acts as an external ligament which acts in restricting excessive joint motion (Laughman et al., 1980). According to Laughman (1980) "the tape, like a ligament, is dependent at its adherence, not throughout its entire length but only at its origin and insertion which, for the ankle, is in areas of minimal soft tissue and motion, thereby favoring maximum adherence" (p. 430). However, the adhesive tape is only as strong as its weakest portion; therefore, strength only at the origin and insertion does not provide maximal ankle support.

Although preventative, ankle taping is commonly performed throughout the scholastic, collegiate, and professional levels of athletics throughout the United States. Opponents of this practice maintain that the joint flexibility and/or overall strength are adversely affected (Abdenour et al., 1979).

Ferguson (1973) reported several negative aspects associated with rourine ankle taping. During the original stages of activity the tape loses up to 40 percent of its original restrictive support. Moisture also accumulates beneath the tape and lessens the adherence to the skin, thus further decreasing its effectiveness. Since tape is applied to a moveable skin, it is unable to give rigid support. Ferguson (1973) also proposed that the muscies of 
the lower leg, particularly the peroneal group, are weakened because they are not used to support the ankle, as the tape provides this support. More specifically, when an athlete is regularly taped they often neglect proper conditioning of these muscles. Finally, the taping prevents the subtalar joint from acting as a safety valve in preventing injuries to the knee and ankle. Ankle taping is viewed as a hazard because it limits the natural safety action of the muscles and tendons (Ferguson, 1973). In his review, Ferguson (1973) also reported that in addition to the 40 percent loosening there is also an increase of approximately 12 percent in the inversion motion allowed at the ankle joint. Ferguson (1973) believed this degree of looseness along with the other drawbacks mentioned previously was too much to advocate routine ankle taping. Experimental research has since refuted Ferguson's position indicating that the pressure of the tape stimulates the peroneals, resulting in earlier and longer stimulation, thus reducing inversion sprains (Glick, Gordon, \& Nishimoto, 1976). These results were obtained by electromyographic study of the peroneals during inversion activity. In addition, Wells (1969) found no significant increase in injury to the knees as a result of ankle taping.

Numerous authors have observed that although the tape does lose its initial restrictive qualities it still provides enough support to lessen the chance of injury (Abdenour et al., 1979; Garrick \& Requa, 1977; Laughman et al., 1980; Malina, Plagnez \& Rarick, 1963; McCluskey \& Blackburn, 1976). Walters et al. (1988) reported that although this loosening occurs, the range of motion restriction is significantly greater than the control condition (no taping) at all time periods.

Numerous studies have reported that as much as 40 percent of the supporting strength provided by adhesive athletic training is lost after approximately ten minutes of exercise (Bunch et al., 1985; Fumich et al., 1981; Glick et al., 1976; Malina, Plagnez \& Rarick 1963; Myburgh et al., 1984; Rarick et al., 1962). Furthermore, no significant support 
from athletic taping may be present following a one hour exercise bout (Myburgh et al., 1984).

The amount of support and protection offered by taping is primarily determined by the taping technique and the resiliency of the tape (Metcalf \& Denegar, 1983). Bunch et al. (1985) found that more than one-third of the ankle support from prophylactic taping procedures can be lost when inexperienced personnel apply the tape; therefore, the tape should be professionally applied. Even when the tape is professionally applied by a certified athletic trainer, variations in technique and tension may be present resulting in variations in the protection provided to the athlete.

Fumich et al. (1981) reported that tape provides a definite restriction of movement immediately following its application. Walters et al. (1988) reported that this restriction is greatest during the preexercise stage. The tape does loosen after exercise but this fact has a beneficial effect. This loosening allows the midrange of subtalar joint movement, allowing this joint to absorb the forces of movement (McCluskey \& Blackburn, 1976).

Seitz and Goldfuss (1984) studied passive ankle motion in relation to restricting inversion. However, the active contraction of the lower leg musculature may be able to overcome the stress passively placed on the lateral ligaments. Therefore, their results may not be applicable to dynamic sport conditions.

Some authors suggest that routine prophylactic ankle taping should only be used as an adjunct to a conditioning or rehabilitation program for the prevention of ankle injury or reinjury (Amheim, 1989; Metcalf \& Denegar, 1983; Roy \& Irvin, 1983; Torg, Vegso, \& Torg, 1987). This rehabilitation program should involve strengthening of the lower leg muscles, especially the peroneals, improvement in Achilles tendon flexibility, and improving of proprioceptive feedback (Arnheim, 1989; Roy \& Irvin, 1983; Torg, Vegso, \& Torg, 1987). 
Ankle Stabilizers. While controversy exists as to the effectiveness of taping, external ankle support devices have recently been introduced as devices to prevent ankle injury (Walters et al., 1988). The introduction of these stabilizers may further complicate the ankle prophylaxis issue.

Walters et al. (1988) evaluated four conditions (control, 3 lace-up braces). These authors reported that two of the devices (Mueller M1 and M2 models) limited range of motion to a degree similar to that of tape. The inversion range of motion restriction of the prophylactic devices was greatest preexercise. Furthermore, inversion range of motion increased after exercise for both prophylactic bracing and athletic taping. The authors suggested that these devices were as effective in restricting ankle and subtalar range of motion and preventing ankle injury as was prophylactic taping. Furthermore, relacing the ankle stabilizers after the exercise bout significantly reduced the range of motion compared with the postexercise time period.

In a recent study by Rovere et al. (1988) a lace-up ankle stabilizer, (Cramer stabilizer) combined with low-top shoes provided greater support than high top shoes and lace-up braces. The authors theorized that this result was due to the easy accessibility to the laces. These authors further concluded that ankle taping was less effective in preventing ankle injury and reinjury than was the laced ankle stabilizer. Also cited was the relative costs of daily prophylactic taping and the use of lace up ankle stabilizers. Rovere et al. (1988) estimate a cost of $\$ 400.00$ per season to tape both ankles of a football player, against a cost of only $\$ 64.00$ for two pairs of lace up ankle stabilizers over the course of the season. Although this study demonstrates the apparent superiority of lace up ankle stabilizers over prophylactic ankle taping, it was retrospective and as such was unable to control all the variables that may have influenced the results. Each player was allowed to chose which prophylactic method (athletic taping or a lace-up ankle stabilizer) they would use during the 
course of the season and could change at any time during the study. This study provides a basis with which to guide further prospective research.

Bunch et al. (1985) reported that tape provided the highest level of support when compared to lace up ankle stabilizers immediately following application. However, tape had the greatest change in support (21 percent) after a 20 minute period of inversion cycles on a mechanical ankle model. The lace up braces had a change of support ranging from 4.5 percent to 8.5 percent after the same 20 minute "exercise" period. There was no statistical difference at the end of the 20 minute "exercise" period between the support given by the tape and the best two lace up braces (Mikros 9 inch, Mueller Sports Medicine, Inc., Prairie du Sac, Wisconsin; Swede-O, North Branch, Minnesota). These authors concluded that the lessened support provided by the lace up ankle stabilizers was most likely caused by the laces coming loose. They reported that the original level of support was restored by relacing the braces.

Several manufacturers of lace-up ankle stabilizers (Cramer Products, Gardner, Kansas; Mueller Sports Medicine, Inc., Prairie du Sac, Wisconsin; Swede-O-Universal, North Branch, Minnesota) claim that these devices restrict range of motion as effectively as adhesive tape. Results of several recent studies have supported the claims of these manufacturers (Bunch et al., 1985; Rovere et al., 1988; Walters et al., 1988).

Myburgh, Vaughn, and Isaacs (1984) found that elastic ankle stabilizers (Futuro ankle brace, Cincinnati, Ohio and Ace ankle brace, Rochelle Park, New Jersey) did not restrict ankle range of motion either before, during or after exercise, and therefore concluded that an elastic ankle brace would not be effective in reducing the severity of ankle injuries. However, these ankle guards were elastic and thus did not provide significant support for the ankle. Most of the commercially available lace-up ankle stabilizers allow for individual fitting and restrictive support. 
Ankle stabilizer manufacturers (Cramer Products, Gardner, Kansas; Mueller Sports Medicine, Inc., Prairie du Sac, Wisconsin; Swede-O-Universal, North Branch, Minnesota) also claim that these prophylactic devices save both time and money (Walters et al., 1988). Bunch et al. (1985), Rovere et al. (1988) and Walters et al. (1988) believe that if these devices and tape are equally effective in restricting excessive ankle motion, retightening the laces as they loosen during activity, would restore the preexercise range of motion restriction of lace-up ankle stabilizers.

Semirigid Orthoses. The Sport-Stirrup ${ }^{\circledR}$ brace (AirCast ${ }^{\circledR}$ Inc, Summit, New Jersey) consists of two hard-plastic molded sides that approximate the ankle medially and laterally and fit into a shoe (Kimura et al., 1987). This form of external support offers ease of application, availability in a variety of sizes, accommodations for the right and left ankles, and provides protection from possible contusions through the use of rigid plastic supports (Kimura et al., 1987). Kimura et al. (1987) reported that the Air-Stirup® provides for individual fitting and may offer some proprioceptive feedback to the athlete during movement.

The Sport-Stirrup ${ }^{\circledR}$ is a prefabricated, semirigid, universal-fitting plastic brace with inflatable air bladders that conform to the contours of the ankle joint complex (Manufacturers' literature). The medial and lateral rigid plastic uprights, external to the air bags, minimally limit dorsiflexion and plantarflexion movements (Burdett et al., 1988; Hoshowsky, 1988; Kimura et al., 1987; Stover, 1980; Stover \& York, 1979; Stover, 1986; Stover \& DeBald, 1986).

The Air-Stirrup $®$, first commercially available in 1979 , was initially designed to function as a rehabilitative device by using the air bladders to create external pressure which, when properly adjusted, helps maintain blood flow and keep swelling to a 
minimum (Kimura et al., 1987). Its construction is similar to other semirigid reusable braces, suggesting that it would be useful in prevention of inversion ankle sprains (Fritschy, Junet, \& Bonvin, 1987; Gross et al., 1987; Hamill, Morin, Clarkson, \& Andres, 1988; Kimura et al., 1987; Stover, 1980; Stuessi, Tiegermann, Gerber, Raemy, \& Stacoff, 1987).

Bunch et al. (1985) found the support provided by external lace-up braces was not dependent on skin adhesion. Furthermore, the semirigid orthoses are constructed of rigid plastic (Stover, 1980). Tape support is dependent on its adherence to the skin and its tensile strength, thus the lace-up stabilizer may provide longer, more consistent support as it does not loosen as moisture accumulates beneath it, nor will the semirigid orthoses lose tensile strength.

\section{Summary}

The lateral aspect of the ankle is the most frequently injured structure in athletics due to the relative weakness of the anatomical support provided by the lateral ligaments (Arnheim, 1989; Booher \& Thibodeau, 1989; Magee, 1987; Roy \& Irvin, 1983). The bony structure of the lateral malleolus provides greater support to the medial aspect. With extreme inversion the medial malleolus may act as a fulcrum to further injure the lateral structures (Arnheim, 1989; Roy \& Irvin, 1983).

During the past three decades, many studies have been conducted to assess the effectiveness of routine closed basketweave ankle taping in the prevention of injury (Abdenour et al., 1985; Davies, 1977; Emerick, 1979; Felder \& McNeely, 1978; Fumich et al., 1981; Garrick, 1977; Garrick \& Requa, 1973; Gross et al., 1987; Hughes \& Stetts, 1983; Laughman et al., 1980; Malina, Plagnez, \& Rarick, 1963; McIntyre, Smith, \& Denniston, 1983; Rarick et al., 1962; Seitz \& Goldfuss, 1984; Simon, 1969; Vandam \& 
Ruhling, 1975). The collective results of these studies suggest that protective taping provides restrictive support which may prevent and/or reduce the severity of ankle injuries. Tape adherence to the skin rapidly decreases in the presence of perspiration and concomitant stress placed upon the tape fibers. However, the protection provided by Gibney closed basketweave adhesive ankle taping techniques is greater than with no ankle support (Glick, Gordon, \& Nishimoto, 1976; Libera, 1972; Malina, Plagnez \& Rarick, 1963; Rarick et al., 1962). Several studies have shown that ankle taping does not increase the probability of sustaining an ankle injury (Garrick \& Requa, 1973; Glick, Gordon, \& Nishimoto, 1976). The empirical conclusions drawn by Ferguson (1973) regarding the ineffectiveness of adhesive tape as a protective support have since been challenged, and refuted in more recent literature (Abdenour et al., 1979; Fumich et al., 1981; Garrick \& Requa, 1973; Gross et al., 1987; Hughes \& Stetts, 1983; Laughman et al., 1980; McIntyre, Smith, \& Denniston, 1983; Seitz \& Goldfuss, 1984). Although adhesive athletic taping has been shown to provide support to the ankle complex, the period of time in which the tape is effective is limited and may not provide adequate protection over the course of an athletic competition.

Lace-up ankle stabilizers appear to provide similar or greater levels of prophylaxis as does tape (Bunch et al., 1985; Gross et al., 1987; Rovere et al., 1988; Walters et al., 1988). As with tape, the brace will also loosen. However, the original level of support of a lace-up ankle brace may be regained by tightening the laces, an option not available with prophylactic ankle taping (Bunch et al., 1985; Rovere et al., 1988; Walters et al., 1988).

Semirigid orthoses have been shown to provide support to an already injured ankle and will allow healing to occur while function is still permitted. It is theorized that an AirStirrup ${ }^{\circledR}$ ankle brace developed specifically for use during training/practice, may provide the best frontal plane support while allowing the most unrestricted sagittal plane ankle 
motion. With the Air-Stirup $®$, ankle plantarflexion and dorsiflexion, essential in running and jumping activities, are virtually unrestricted (Gehlsen, Pearson, \& Bahamonde, 1989; Gehlsen, Pearson, \& Bahamonde, 1991). Excessive ankle inversion, an etiology in 85 percent of all ankle injuries, would be restricted providing prophylaxis for inversion ankle injuries.

Current research has focused on the relative degree of ankle protection provided by athletic taping, lace up ankle stabilizers, and semirigid orthoses. Previous research has utilized either mechanical models or static comparisons of these devices. There is a lack of controlled, direct comparison studies between each of these prophylactic devices in relationship to one another in a dynamic sport situation. 


\section{CHAPTER 3}

\section{METHODS}

Introduction

The purpose of this study was to measure and compare the effectiveness of closed basketweave inversion ankle taping, a lace-up ankle stabilizer (Swede-O-Universal, North Branch, Minnesota), and a semirigid ankle orthotic device (Sport-Stirrup®) ankle brace ${ }^{\mathrm{IM}}$, Summit, New Jersey) in limiting ankle inversion under dynamic loads imposed by repetitive walking and running on a treadmill tilted laterally (5\% road grade; 6.5 degrees) before and after a 20 minute exercise bout.

In this chapter the testing procedures and methodology are discussed. The subjects' qualifications, experimental protocol, instrumentation, and data analysis procedures will be presented.

\section{Subjects}

The subjects who participated in this study were volunteers between 19 and 30 years of age. This age range was selected as it is comparable to the ages of competitive athletes who would routinely use ankle prophylaxis during activity. The subjects were recruited by volunteer solicitation in an introductory athletic training class within the Department of Human Performance at San Jose State University during the spring semester 1990. The purpose of the study and the protocol for data collection were explained to the students solicited. Potential subjects had the opportunity to ask any questions about the study prior to stating their willingness to be considered as a subject. Prior to participation in this study, each subject gave informed consent in accordance with the guidelines established by 
San Jose State University's Institutional Review Board for Human Subjects (see Appendix A).

Potential subjects were screened prior to selection and met the following criteria for inclusion in the study: (a) no reported history of significant injury (second degree or greater) to either ankle; (b) possession of normal feet; and (c) were not participating in professional or collegiate sports, so as not to become injured in their sports and therefore be lost to the study.

\section{Experimental Protocol}

Subjects were asked to read and sign a human subjects informed consent form in accordance with University policy and complete a subject information sheet regarding their age, height, and weight during their first test session.

Four separate test sessions were required to collect data, one for each of four experimental conditions. All four sessions were conducted within a one-week period, every other day for four days. The first session took approximately 60 minutes per subject to complete as the subjects read and signed the informed consent form and tested the first experimental condition. Subsequent testing sessions were approximately 40 minutes per subject in length.

The order in which subjects perform the experimental conditions was counterbalanced (see Figure 4). All testing was done on the subject's right ankle. The control condition (no prophylaxis) was compared to each of the prophylactic supports only on the right side, thus eliminating the need for a specific control group.

The first data collection session proceeded as follows: application of the first experimental condition, active inversion range of motion measurements on the right ankle, marking of the anatomical reference points, preexercise videotaping on the treadmill, 
Figure 4. Condition order.

CONDITION

(1)

(2)

(3)

(4)

\section{QRDER}

2

4

3

4

3

2

43

4

1

$$
\begin{aligned}
& 1 \text { = Control Condition } \\
& 2 \text { = Closed Basketweave Athletic Taping } \\
& 3=\text { Lace-up Ankle Stabilizer } \\
& 4=\text { Semirigid Orthosis }
\end{aligned}
$$


stationary cycling, completion of the obstacle course, and finally postexercise videotaping on the treadmill.

The active inversion range of motion measurement were recorded in degrees using a plastic, handheld goniometer. These measurements were made with the subject's ankle in an anatomically neutral position to eliminate the plantarflexion/dorsiflexion variable (Hughes \& Stetts, 1983).

Prior to the preexercise experimental bout on the treadmill, the following anatomical reference points were marked on each subject: the center of the popliteal space as determined by measuring the distance between the fibular head and Gurdy's tubercle and taking the midpoint of these strucrures, the Achilles tendon at the level of the subtalar joint, and the distal end of the calcaneus at it's apophysis (Kimura et al., 1987) (see Figure 5). These reference points were either marked directly on the prophylactic device or on the socks of the subjects. Once these points were marked the subject completed the preexercise videotaping on the readmill.

Stationary cycling (Model 818, Monarch, Valberg, Sweden), five minutes at 60-90 revolutions per minute and 20 Newtons of resistance, served as a warmup after the application of the experimental condition and the preexercise tesing and prior to participation in the obstacle course. The obstacle course was used to simulate athletic activity associated with practice or game conditions, as it has been documented that such activity results in the loosening of prophylactic ankle devices (Emerick, 1979; Ferguson, 1973; Fumich et al., 1981; Glick, Gordon, \& Nishimoto, 1976; Gross et al., 1987; Hughes \& Stetts, 1983; Laughman et al., 1980; Malina, Plagenz, \& Rarick, 1963; McIntyre, Smith, \& Denniston, 1983; Myburgh, Vaughn, \& Isaacs, 1984; Rovere et al., 1988; Seitz \& Goldfuss, 1984; Walters et al., 1988). The obstacle course was patterned after Robinson, Frederick, and Cooper (1986) and consisted of straight ahead sprinting, 
Figure 5. Anatomical reference points.

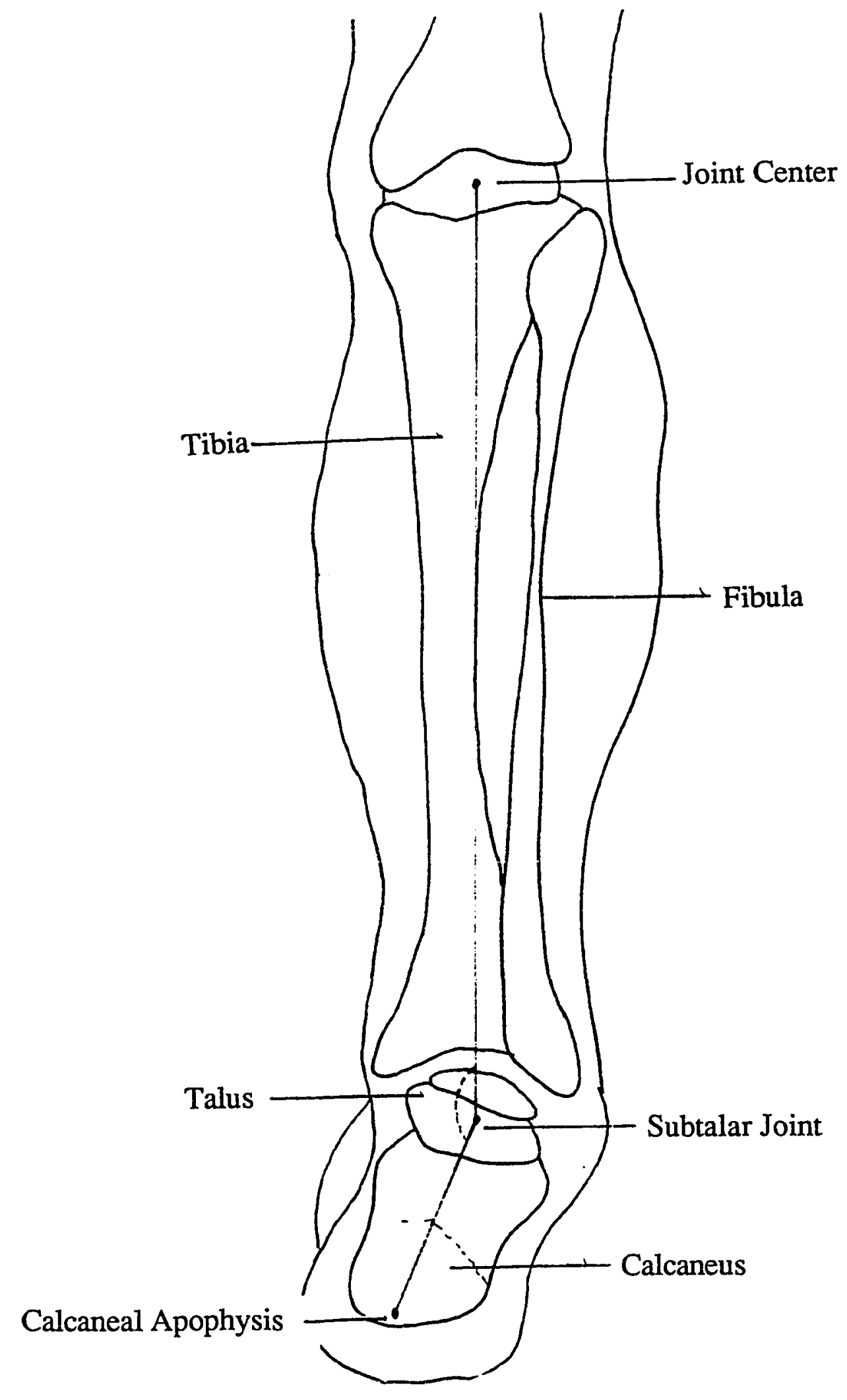


side to side activities, vertical jumping and backward running (see Figure 6). An explanation of the maneuvers associated with the obstacle course was given while walking through the course. The subjects successively completed the obstacle course for a total of 20 minutes with rest intervals spaced according to subject tolerance. They then proceeded to the testing area to complete the postexercise experimental protocol on the treadmill.

Following each subjects' final test session they were asked to subjectively rank on a Likert-type scale each of the three support devices as to their relative comfort and feeling of support. This ranking was recorded on the data collection sheet for each individual subject (see Appendix B).

The second through fourth data collection sessions proceeded as follows: test condition application (control, tape, lace-up brace, semirigid orthosis), active inversion measurements, preexercise videotaping of treadmill performance, stationary cycling, completion of obstacle course, and postexercise videotaping of treadmill walking and running performance.

\section{Instrumentation}

A laterally tilted treadmill (Quinton, Model 18-60, Seattle, Washington) (5\% road grade; 6.5 degrees) was used to dynamically load the ankle and subtalar joints. This device has been shown, through pilot study and research study, to allow the subtalar joint to be put into inversion without substantial risk of injury to the subjects (Gehlsen, Pearson, \& Bahamonde, 1989; Gehlsen, Pearson, \& Bahamonde, 1991). Had a subject been injured while participating in the study, he/she would have been taken to the University health center for evaluation and treatment.

One high speed video camera (Panasonic Model AG-450, Osaka, Japan) was utilized to provide two dimensional data concerning the amount of ankle motion subjects experience 
Figure 6. Obstacle course.

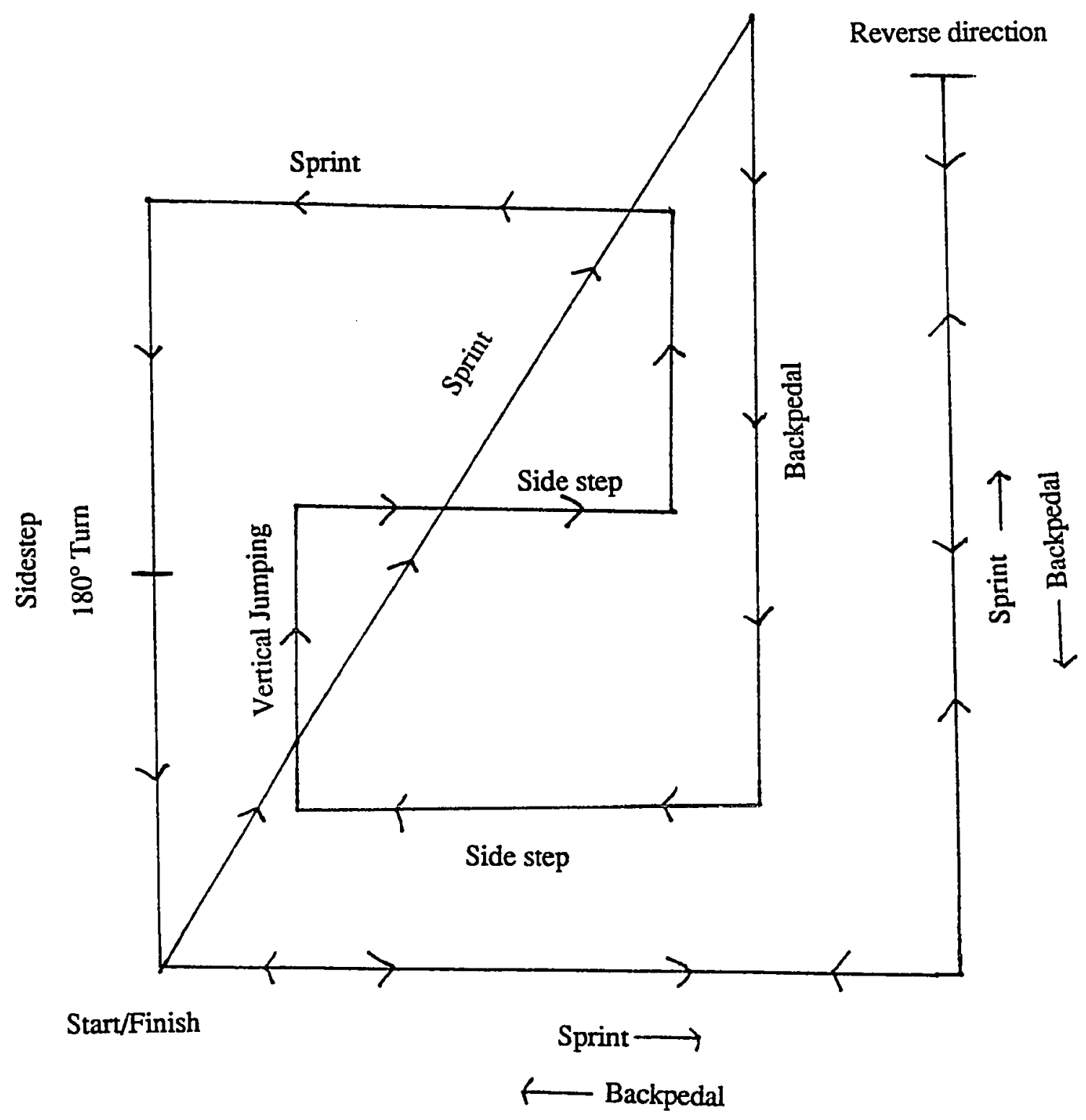


while they exercised on the treadmill. The framing rate of the video cameras was 60 fields per second with an exposure rate of $1 / 250$ th second. The camera was placed behind the subject, perpendicular to the frontal plane of motion (see Figure 7). The camera was placed 4.5 meters behind the subject and the zoom was set to capture mid-torso to the base of the treadmill. The video camera was leveled before each test session and set up in the same place for all test sessions.

Ankle Prophylactic Devices. Ankle prophylactic device support increases stability by reinforcing the ligamentous structures of the ankle joint and restricts extreme motion (Bullard, Dawson, \& Arenson, 1979; Hughes \& Stetts, 1983; Libera, 1972). The primary objective of any external support is to prevent inversion sprains through restriction of available inversion (Bullard, Dawson, \& Arenson, 1979; Libera, 1972). By restricting active inversion, the motion available to the athlete at the extremes of inversion will also be limited (Hughes \& Stetts, 1983). Ankle prophylaxis should also support the joint during activity and prevent hypermobility of the ankle without severely inhibiting the normal biomechanics of motion (Bullard, Dawson, \& Arenson, 1979; Libera, 1972).

Closed Basketweave Ankle Taping. Athletic adhesive tape, 3.75 centimeters in width (Zonas ${ }^{\mathrm{TM}}$ Porous, Johnson and Johnson Co., New Brunswick, New Jersey) was used. The lower leg and ankle was sprayed with tape adhesive (QDA ${ }^{\mathrm{TM}}$, Cramer Products, Inc., Gardner, Kansas) to provide a secure area for tape application. Pretaping underwrap (Mueller Sports Medicine, Inc., Prairie du Sac, Wisconsin) was used to cover the lower leg before application of the tape as this is the common method for routine ankle taping.

The taping technique used was a combination Gibney basketweave, stirrups, and a continuous figure- 8 heel lock as described by Rarick et al. (1962). The tape was applied 
Figure 7. Test area view from video camera.

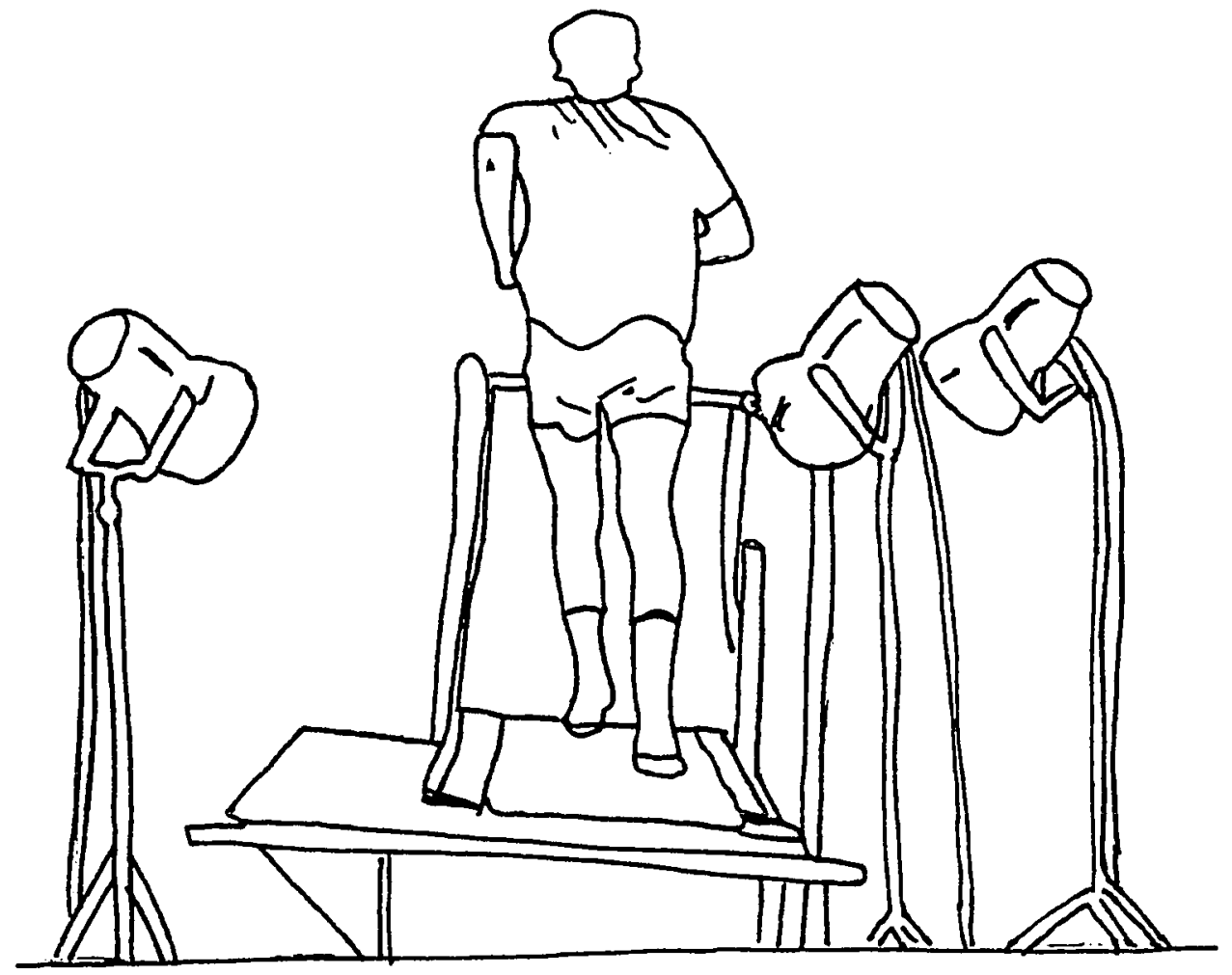


following the application of a tape adherent, sponge heel and lace pads "lubricated" with Skin Lube (Cramer Products, Inc., Gardener, Kansas), and a thin layer of underwrap, as this procedure is common in the routine taping of athletes.

Two anchor strips were anchored to the skin at the musculotendinous junction of the gastrocnemius and Achilles tendon and two anchor strips around the instep of the foot. Following the anchor application, the basketweave was applied. A total of three stirrups and three horseshoe strips were used. One stirrup was applied and then one horseshoe until all three strips were applied. Two continuous heel locks were wrapped under the foot, behind the heel, and around the lower leg.

Davies (1977) suggested application of heel locks with a medial to lateral force to slightly evert the foot away from the sprain mechanism. Felder (1978) emphasized stirrup application with medial to lateral force, thus placing the ankle into a slightly everted, pronated position. These recommendations were followed in the taping of the subjects.

All ankle taping was done by the same certified athletic trainer. Each subject had both ankles taped for safety.

\section{Lace-Up Ankle Stabilizer. The Swede-O-Universal@ lace-up ankle stabilizer} (Swede-O-Universal, North Branch, Minnesota) was used by each subject during the brace testing. Subjects were fitted with the appropriate size brace based upon manufacturer's guidelines, that is, in accordance with their shoe size. The lace-up stabilizer was worn over the top of the subjects' socks (see Figure 8).

Ankle stabilizer application was explained and demonstrated to each subject according to the manufacturer's protocol. The application of the brace was supervised by the primary investigator to insure that it was done correctly. The brace was considered properly applied when the subject was unable to rotate the brace side-to-side. The laces of the brace were 
Figure 8. Lace-up ankle stabilizer.

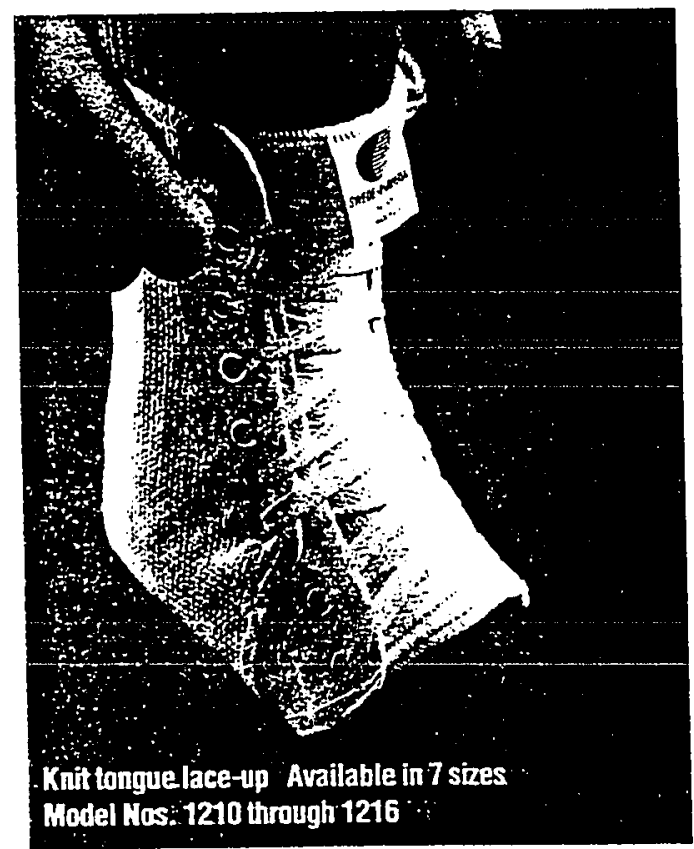


double knotted to prevent them from becoming untied during the test session. Once the brace was tightened it was not retightened for the duration of the experimental session. This allowed measurement of the amount of restriction before and after the exercise bout.

Semirigid Orthotic Device. The Sport-Stirrup ${ }^{\circledR}$ ankle brace ${ }^{\mathrm{TM}}$ (AirCast Co., Summit, New Jersey) was used for the semirigid orthosis experimental condition. The application of the semirigid orthosis was explained and demonstrated to each subject. The SportStirrup® allows individual fitting by adjusting the air pressure in each of the upright air bladders to accommodate various lower leg sizes. The application was supervised by the investigator to ensure proper fit. As with the ankle stabilizer, the semirigid orthosis was considered to be properly applied when it could not be moved side-to-side on the lower leg and was worn over the subjects' socks. Semirigid orthoses were worn on both ankles during the testing session (see Figure 9).

\section{Data Analysis}

Subject information was recorded on a master data recording sheet (see Appendix C). The test condition order and test ankle was also noted. The subject's maximal inversion angle for each of the three test supports were recorded for eight foot strikes on the treadmill. Videotape for each of the four experimental conditions for each subject was digitized using the Two Dimensional Peak Performance software and stored on floppy disk.

Field-by-field analysis of videotape was used to measure ankle and subtalar joint angles in the frontal plane. Only the maximal inversion angle was used in the analysis. This maximal angle was determined by digitizing every second video field.

The Peak Performance system allows calculation of the angle occurring at the subtalar 
Figure 9. Sport-Stirrup( $\left.{ }^{(}\right)$ankle brace ${ }^{\mathrm{TM}}$.
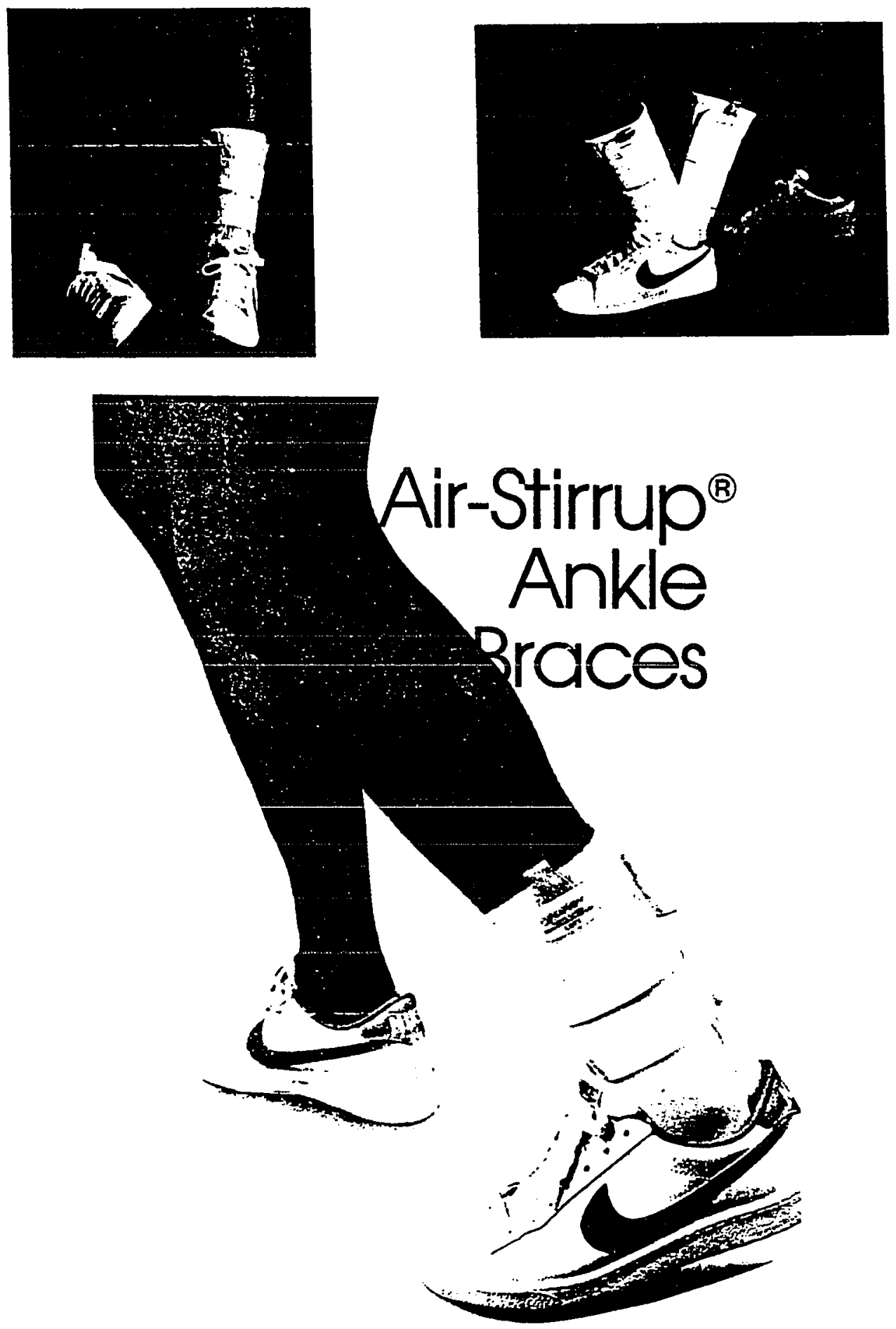
joint as it was stressed by the treadmill while walking and running. Data for the $4 \mathrm{mph}$ trials were "smoothed" at a setting of four and the data for the $9 \mathrm{mph}$ trials were "smoothed" at seven.

Statistical analysis consisted of a two-way repeated measures analysis of variance (ANOVA) at both four and nine miles per hour for the average maximum inversion angle. A two-way repeated measures ANOVA was also completed for the maximum voluntary inversion measurements. Two separate two-way repeated measures ANOVAs were completed, the first for the $4 \mathrm{mph}$ condition and the second for the $9 \mathrm{mph}$ condition. The independent variables were condition and time and the dependent variable was the average maximum inversion angle. Scheffe' post hoc analysis was completed to determine where significant differences occurred. Results were considered significant at the .01 alpha level (.05 divided by 4 due to multiple $\mathrm{E}$ values). Based on the subject's subjective rankings for comfort and support for each of the prophylactic devices, Chi square tests of independence were examined to determine whether or not significant relationships existed between the subjective ranking of comfort and support.

Data analysis was completed using SPSS PC+ software (Software Package for Social Sciences, 10th Edition, Chicago, Ilinois) housed on an IBM compatible microcomputer at San Jose State University. All paperwork, videotape, floppy disks, and data associated with this research study were locked in SPX 208, in a file cabinet located at the primary investigators home, or in the possession of the primary investigator.

\section{Summary}

This chapter contains the testing protocol and methodology. The subjects' qualifications, experimental protocol, instrumentation, and data analysis procedures were discussed. Ten healthy subjects were recruited to participate in the study. They 
participated in each of the four test conditions: control (no prophylaxis), adhesive taping, lace-up ankle stabilizer, and a semirigid orthosis. For each test session the subjects proceeded as follows: first, the experimental condition was applied; second, preexercise videotaping occurred; third, they completed an obstacle course and; fourth, had their performance videotaped on a laterally tilted treadmill. All pertinent subject information was recorded. The average maximum inversion angle for the eight foot strikes on the treadmill served as the test angle. These angles were used to quantify the effectiveness of each external ankle prophylaxis evaluated in the study. Following the final test session, each subject completed a subjective evaluation of the four test devices for perceived comfort and support. 


\section{CHAPTER 4}

\section{RESULTS AND DISCUSSION}

\section{Introduction}

The purpose of this study was to measure and compare the effectiveness of closed basketweave inversion ankle taping, a lace-up ankle stabilizer (Swede-O-Universal, North Branch, Minnesota), and a semirigid ankle orthotic device (Sport-Stirrup\& ankle brace, Summit, New Jersey), in limiting ankle inversion under dynamic loads imposed by repetitive walking and running on a treadmill laterally tilted (5\% road grade; 6.5 degrees) before and after a 20 -minute exercise bout. The analysis of data will be presented in the following sections: (a) description of subjects, (b) active range of motion comparisons, (c) average maximum inversion angles, and (d) subjective rankings of the devices by the subjects.

\section{Description of Subjects}

The subjects in this study consisted of students from within the Department of Human Performance at San Jose State University. Ten subjects (5 male; 5 female) with an average age of 23.40 years (SD 2.46) volunteered to participate in this investigation. None of the subjects had a history of ankle injury and presented with a mean passive inversion measurement of $18.40^{\circ}$. Individual subject and group characteristics are presented in Table 1. 
Subject and group characteristics.

Passive Condition

\begin{tabular}{ccccccc} 
Subject & Gender & Age & Height $(\mathrm{cm})$ & Weight(kg) & Angle & Order \\
\hline 1 & F & 21 & 164.5 & 63.3 & $17^{\circ}$ & $2^{*}$ \\
2 & F & 29 & 174.0 & 66.4 & $17^{\circ}$ & 4 \\
3 & M & 23 & 178.0 & 82.8 & $15^{\circ}$ & 4 \\
4 & M & 26 & 190.0 & 87.1 & $25^{\circ}$ & 4 \\
5 & M & 21 & 173.8 & 63.5 & $21^{\circ}$ & 2 \\
6 & F & 22 & 167.0 & 62.4 & $16^{\circ}$ & 1 \\
7 & F & 22 & 168.0 & 56.5 & $15^{\circ}$ & 3 \\
8 & F & 24 & 164.2 & 70.9 & $20^{\circ}$ & 3 \\
9 & M & 23 & 171.2 & 70.0 & $18^{\circ}$ & 1 \\
10 & M & 23 & 162.5 & 54.1 & $200^{\circ}$ & 3 \\
\hline & M & 23.40 & 171.32 & 67.70 & $18.40^{\circ}$ & $3.13^{\circ}$ \\
& SD & 2.46 & 8.24 & 10.53 & &
\end{tabular}

\section{*CONDITION ORDER}

NUMBER OF SUBJECTS $(\mathrm{N}=10)$

1 - Control; tape; lace-up stabilizer, semirigid orthosis

2 - Tape; semirigid orthosis; control; lace-up stabilizer

3 - Lace-up stabilizer, control semirigid orthosis; tape

4 - Semirigid orthosis; lace-up stabilizer; tape; control 


\section{Active Inversion Measurements}

The lace-up ankle stabilizer allowed the least amount of active ankle motion both preexercise $\left(7.60^{\circ}\right)$ and postexercise $\left(11.70^{\circ}\right)$. The most change in active inversion preexercise to postexercise occurred with the tape condition $\left(9.90^{\circ}\right.$ to $\left.16.30^{\circ}\right)$, for a change of $6.40^{\circ}$.

\section{Average Maximum Inversion Angle Measurements}

Videotape analysis was used to determine the maximum angle for each foot strike for each subject for each of the four test conditions at four and nine miles per hour. The average maximum inversion angle (AMIA) for each subject was then determined by adding each of the individual subject's maximum inversion angle from eight foot strikes and dividing by eight.

There were some discrepancies in the average maximum inversion angles. For example, at $9 \mathrm{mph}$ the preexercise angle is greater than the postexercise angle for the control condition. In addition, the postexercise AMIA at both $4 \mathrm{mph}$ and $9 \mathrm{mph}$ for the tape condition are greater than the control condition. These discrepancies may be due to the relatively low number of subjects that participated in the study and/or a lack of experience by the subjects running on a laterally tilted treadmill.

The two way repeated measures ANOVAs revealed significant differences $(p<.01)$ in AMIA among the ankle devices at $4 \mathrm{mph}$ and also between the devices at $9 \mathrm{mph}$. In addition, significant differences ( $\mathfrak{k}<.01)$ were found between preexercise and postexercise inversion measurements at $4 \mathrm{mph}$. Scheffe' post-hoc analyses indicated significant differences ( $\mathbf{p}<.01$ ) in AMIA between the control condition (no prophylaxis) and semirigid orthosis at both $4 \mathrm{mph}$ and $9 \mathrm{mph}$ and between the control condition and lace-up ankle stabilizer at $4 \mathrm{mph}$. In general, at both 4 and $9 \mathrm{mph}$ the semirigid orthosis provided the 
most inversion restraint followed by the lace-up ankle stabilizer, closed basketweave inversion ankle taping, and the control condition.

\section{Subjective Rankings}

The subjects were asked to rate each of the support devices on a 5-point Likert scale for both perceived comfort and support (see Appendix B). No significant relationships were found for any of the prophylactic support devices for comfort and support. Subjective rankings revealed that four of the ten subjects rated the lace-up ankle stabilizer as both most supportive and most comfortable. Additionally, two of the ten subjects felt the semirigid orthosis was both most supportive and most comfortable. Only one subject felt that athletic taping was both most comfortable and supportive.

\section{Summary}

The results of this study suggest that the semirigid orthosis provided the greatest ankle inversion range of motion followed by the lace-up ankle stabilizer and finally closed basketweave athletic taping. The two-way repeated measures ANOVAs revealed significant differences in AMIA among the ankle devices at $4 \mathrm{mph}$ and also between the devices at $9 \mathrm{mph}$. Additionally, significant differences were found between preexercise and postexercise inversion measurements at $4 \mathrm{mph}$. Scheffe' post-hoc analyses indicated significant differences in AMIA between the control condition (no prophylaxis) and the semirigid orthosis at both $4 \mathrm{mph}$ and $9 \mathrm{mph}$ and between the control condition and the laceup ankle stabilizer at $4 \mathrm{mph}$. However, these findings are at best tentative since the sample size was so small and the assumptions of the ANOVA procedure were violated. 


\section{Discussion}

Prophylactic ankle supports are applied to support the lateral ankle complex by externally restricting inversion range of motion. By restricting active inversion, the movement available to the individual at the physiological extremes of motion will also be limited. Each of the three prophylactic devices tested in this study are assumed to limit excessive ankle motion by passive restraint, functioning as an external ligament, The semirigid orthosis restrains calcaneal motion, while athletic taping and the lace-up stabilizer control excessive movement at both the calcaneal and forefoot regions to limit the anatomical extremes of inversion range of motion. Several researchers have suggested that external supports may be beneficial in providing ligament protection as long as normal joint mechanics are not compromised (Abdenour et al., 1979; Gross et al., 1987; Kimura et al., 1987; Seitz \& Goldfuss, 1984). The results of this study indicated that the lace-up ankle stabilizer and the semirigid orthosis support devices were similar in restricting inversion range of motion prior to exercise and the athletic taping provided the least preexercise range of motion restriction.

Although each prophylactic device provided increased protection before exercise, a more important consideration of these devices is their ability to protect the ankle from injury by providing support during exercise. The findings of this study indicated significant differences in the levels of support after a specific type and duration of exercise. Closed basketweave ankle taping provided the least support after the 20 minute exercise session at both the 4 and 9 mile per hour conditions. This finding supports the results of Fumich et al., (1981) and Rarick and associates (1962), who reported similar loss of restrictive effects following exercise.

Previous research suggests that the loosening of adhesive tape might be attributed to a separation or tearing of fibers resulting from mechanical strain and moisture on the skin 
surface, which adversely affects the tapes adhesive qualities (Bunch et al., 1985; Hughes \& Stetts, 1983; Rarick, Bigley, \& Karst, 1962; Rovere et al., 1988). These suggestions may have been the cause for the loosening of the adhesive tape following the completion of the obstacle course. The athletic taping did provide some inversion restraint following the exercise session. However, it is unknown whether this restriction is adequate to prevent either the frequency or severity of inversion ankle injury.

After exercise the lace-up ankle stabilizer had loosened by $1.93^{\circ}$ at $4 \mathrm{mph}$ and $1.47^{\circ}$ at $9 \mathrm{mph}$ when compared to preexercise measurements. The elasticity required to pull the brace over the foot may become further stretched during exercise. Also, the laces may have loosened sufficiently to compromise the brace's initial support. Therefore, these may be the determining factors for the loss of restrictive capabilities of the lace-up stabilizer.

In general, the semirigid orthosis provided the greatest inversion restraint after exercise as determined by the average maximum inversion angle. The ankles braced with the semirigid orthosis demonstrated a $3.26^{\circ}$ loss of motion restriction at $4 \mathrm{mph}$ and $1.40^{\circ}$ at $9 \mathrm{mph}$ after 20 minutes of exercise. It is evident from this data that the semirigid orthosis was superior to both the lace-up ankle stabilizer and athletic taping in retaining a higher degree of their original support. These results are consistent with Gross et al., (1987) who reported significantly higher range of motion restriction for a semirigid orthosis when compared to athletic taping following exercise. The semirigid design of this prophylactic support suggests that this device might be more stable than fabric supports or athletic tape because of their nondeforming material and, therefore, should be able to resist more favorably the stresses of athletic participation. However, the semirigid orthosis evaluated in this study did loosen to some degree following the 20 minute exercise period. This loosening might be due to slippage of the Velcro® (Velcro USA Inc., Manchester, New Hampshire) straps during exercise, moisture accumulation between the socks and semirigid 
orthosis, or slippage of the brace against the lower leg and ankle. Support may be enhanced when the semirigid orthosis is worn with a shoe. The subjects were instructed not to retighten these straps during the course of the test session; however, such tightening may return the semirigid orthosis to preexercise levels of motion restriction. In addition, some secondary school football leagues prohibit the wearing of any protective device which is rigid in nature. In such instances the semirigid orthosis would not be permitted and another method of ankle prophylaxis must be considered. A summary of the degree of range of motion restriction is presented in Table 2.

Following completion of all testing sessions the subjects completed a survey to rank each of the support devices for (a) perceived comfort and (b) support. Four of the ten subjects rated the lace-up stabilizer as both most comfortable and most supportive. Both comfort and support seem to be important considerations when selecting a support system. It is unlikely that an athlete would wear a device they consider uncomfortable or unsupportive regardless of the devices' objective merits.

This study offers information regarding the comparative support effectiveness of closed basketweave ankle taping, a lace-up stabilizer, and a semirigid orthosis before and after a 20 minute exercise session. These results are particularly relevant to those involved in the prevention and management of ankle injuries. The data in this study suggested the relative ineffectiveness of athletic taping in restricting ankle inversion range of motion following exercise. Overall, the support provided by both the lace-up ankle stabilizer and the semirigid orthosis was more favorable than that of taping.

Also apparent was the difference between the semirigid orthosis and the lace-up ankle stabilizer. The semirigid orthosis provided the most inversion restraint followed by the lace-up ankle stabilizer, ankle taping, and the control condition when compared at both a walking ( $4 \mathrm{mph}$ ) and running $(9 \mathrm{mph})$ pace. These results suggest that the semirigid 
Table 2

Average maximum inversion angle measurements.

Control Tape $\quad$ Lace-up $\quad$ Semirigid Orthosis

Preexercise

$\begin{array}{llllr}4 \mathrm{mph} & 14.97 & 10.65 & 10.61 & 7.60 \\ 9 \mathrm{mph} & 18.21 & 11.90 & 10.91 & 10.31\end{array}$

Postexercise

$\begin{array}{lllll}4 \mathrm{mph} & 15.76 & 15.90 & 12.54 & 10.86 \\ 9 \mathrm{mph} & 16.87 & 19.44 & 12.38 & 11.71\end{array}$


orthosis may be more effective than either the lace-up ankle stabilizer or ankle taping in the prevention of inversion ankle sprains. 


\section{CHAPTER 5}

\section{SUMMARY, CONCLUSIONS, AND RECOMMENDATIONS}

\section{Introduction}

The purpose of this study was to measure and compare the effectiveness of closed basketweave inversion ankle taping, a lace-up ankle stabilizer (Swede-O-Universal, North Branch, Minnesota), and a semirigid ankle orthotic device (Sport-Stirrup $\Re$ ankle brace, Summit, New Jersey), in limiting ankle inversion under dynamic loads imposed by repetitive walking and running on a treadmill tilted laterally ( $5 \%$ road grade; 6.5 degrees) before and after a 20 -minute exercise bout.

This chapter will present a summary of this investigation, the conclusions reached based on data analysis and recommendations for future research.

\section{Summary}

Based strongly upon tradition and empirical claims, adhesive ankle taping remains the primary method of providing athletes with prophylactic ankle support. Recently, the use of lace-up ankle stabilizers has been proposed as an alternative to prophylactic ankle taping. Semirigid orthotic devices, originally designed to protect an injured ankle as it healed, have also been suggested as an alternative to both adhesive taping or lace-up types of ankle stabilization for the prevention of pathologic ankle motion.

Experimental results are conflicting with regard to the effectiveness of these ankle supports. While some studies found taping to be effective compared to controls, others have reported extreme limitations to that support. Recent in vitro as well as epidemiologic studies have cited lace-up ankle stabilizers as devices that provided significant, prolonged 
ankle protection. The semirigid orthotic device may provide equal or greater ankle support when compared to adhesive ankle taping due to its semirigid structure and Velcro® (Velcro USA Inc., Manchester, New Hampshire) fastening system, which limits loosening during activity.

The lateral aspect of the ankle is the most frequently injured structure in athletics due to the relative weakness of the anatomical support provided to the lateral ligaments (Amheim, 1989; Booher \& Thibodeau, 1989; Magee, 1987; Roy \& Irvin, 1983). Bony structure of the medial malleolus provides greater support to the medial aspect, and may, with extreme inversion, act as a fulcrum to further injure the lateral structures (Arnheim, 1989; Roy \& Irvin, 1983).

During the past three decades, many studies have been conducted to assess the effectiveness of routine closed basketweave ankle taping in the prevention of injury (Abdenour et al., 1985; Davies, 1977; Emerick, 1979; Felder \& McNeely, 1978; Fumich et al., 1981; Garrick, 1977; Garrick \& Requa, 1973; Gross et al., 1987; Hughes \& Stetts, 1983; Laughman et al., 1980; Malina, Plagnez, \& Rarick, 1963; McIntyre, Smith, \& Denniston, 1983; Rarick et al., 1962; Seitz \& Goldfuss, 1984; Simon, 1969; Vandam \& Ruhling, 1975). The collective results of these studies suggest that protective taping provides restrictive support which may prevent and/or reduce the severity of ankle injuries. Tape adherence to the skin rapidly decreases in the presence of perspiration and concomitant stress placed upon the tape fibers. However, the protection provided by Gibney closed basketweave adhesive ankle taping techniques is greater than with no ankle support (Glick, Gordon, \& Nishimoto, 1976; Libera, 1972; Malina et al., 1963; Rarick et al., 1962). Several studies have shown that ankle taping does not increase the probability of sustaining an ankle injury (Garrick \& Requa, 1973; Glick, Gordon, \& Nishimoto, 1976). The empirical conclusions drawn by Ferguson (1973), regarding the 
ineffectiveness of adhesive tape as a protective support have since been challenged, and refuted in more recent literature (Abdenour et al., 1979; Fumich et al., 1981; Garrick \& Requa, 1973; Gross et al., 1987; Hughes \& Stetts, 1983; Laughman et al., 1980; McIntyre, Smith, \& Denniston, 1983; Seitz \& Goldfuss, 1984). Although adhesive athletic taping has been shown to provide support to the ankle complex, the period of time in which the tape is effective is limited and may not provide adequate protection over the course of an athletic competition.

Lace-up ankle stabilizers appear to provide similar or greater levels of prophylaxis as does tape (Bunch et at., 1985; Gross et al., 1987; Rovere et al., 1988; Walters et al., 1988). As with tape, the brace will also loosen. However, the original level of support of a lace-up ankle brace may be regained by tightening to laces, an option not available with prophylactic ankle taping (Bunch et al., 1985; Rovere et al., 1988; Walters et al., 1988).

Semirigid orthoses have been shown to provide support to an already injured ankle and will allow healing to occur while function is still permitted. It is theorized that an AirStirrup ${ }^{\circledR}$ ankle brace developed specifically for use during training/practice, may provide the best frontal plane support while allowing the most unrestricted sagittal plane ankle motion. With the Air-Stirrup $®$, ankle plantarflexion and dorsiflexion, essential in running and jumping activities, are virtually unrestricted (Gehlsen, Pearson, \& Bahomonde, 1989; Gehlsen, Pearson, \& Bahomonde, 1991). Excessive ankle inversion, an etiology in 85 percent of all ankle injuries, would be restricted to provide prophylaxis for inversion ankle injuries.

Ten healthy subjects were recruited to participate in the study. They participated in each of the four test conditions: control (no prophylaxis), adhesive taping, lace-up ankle stabilizer, and a semirigid orthosis. First, the experimental condition was applied; second, preexercise videotaping occurred; third, they completed an obstacle course and again had 
their performance videotaped on a laterally tilted treadmill. All pertinent subject information was recorded. The average maximum inversion angle derived from eight foot strikes on the treadmill served as the test angle. These angles were used to quantify the effectiveness of each external ankle prophylaxis evaluated in the study. Following the final test session for each subject, they completed a subjective evaluation of the four test devices for perceived comfort and support.

Two-way repeated measures ANOVAs revealed significant differences $(p<.01)$ in average maximum inversion angle (AMIA) between the ankle devices at $4 \mathrm{mph}$ and also between the devices at $9 \mathrm{mph}$, and between preexercise and post exercise inversion measurements at $4 \mathrm{mph}$. Scheffe' post hoc analyses indicated significant differences ( $\mathrm{Q}<.01$ ) in AMIA between the control condition (no prophylaxis) and the semirigid orthosis at both $4 \mathrm{mph}$ and $9 \mathrm{mph}$, and between the lace-up ankle stabilizer at $4 \mathrm{mph}$ ). At both 4 $\mathrm{mph}$ and $9 \mathrm{mph}$ the semirigid orthosis provided the most inversion restraint, followed by the lace-up brace, closed basketweave taping, and the control condition. Prophylactic taping provided the least amount of preexercise and postexercise inversion constraint, as measured by AMIA.

\section{Conclusions}

In this study, the support provided by the three prophylactic ankle supports was objectively measured before and after a 20-minute exercise session. Based on the results of this study, the following conclusions would appear to be warranted:

1. Before exercise, each of the support devices was effective in providing ankle inversion range of motion restriction. The semirigid orthosis and lace-up ankle stabilizer provided more restriction than ankle taping. 
2. The taped ankle showed an initial average inversion range of motion restriction of $10.65^{\circ}$ at $4 \mathrm{mph}$ and $11.90^{\circ}$ at $9 \mathrm{mph}$, which was reduced to $15.90^{\circ}$ and $19.44^{\circ}$ respectively following 20 minutes of exercise. Secondly, the lace-up ankle stabilizer provided a restriction of $10.61^{\circ}$ at $4 \mathrm{mph}$ and $10.91^{\circ}$ at $9 \mathrm{mph}$ before exercise and $12.54^{\circ}$ and $12.38^{\circ}$ after exercise. Thirdly, the semirigid orthosis provided $7.60^{\circ}$ and $10.31^{\circ}$ before exercise and $10.86^{\circ}$ and $11.71^{\circ}$ after.

3. Closed basketweave inversion ankle taping demonstrated the most loss in mechanical restriction following the 20 minute exercise session.

4. Following exercise, the semirigid orthosis provided the most inversion restraint followed by the lace-up ankle stabilizer, ankle taping, and the control condition at both $4 \mathrm{mph}$ and $9 \mathrm{mph}$.

5. Subjective responses from the subjects showed no ranked preference on the criteria of perceived comfort and support.

6. The semirigid orthosis may be more effective than the other prophylactic devices tested in preventing inversion ankle sprains and may be beneficial for individuals with chronic lateral joint instability.

\section{Recommendations for Future Research}

1. Increase the angle of the treadmill and use different speeds on the treadmill, more representative of sport participation.

2. Use subjects with laxity and/or previous injury to determine in any of the prophylactic devises provide adequate protection from reinjury.

3. Use a faster speed camera, i.e., $100 \mathrm{~Hz}$. 
4. Film an actual sport movement or skill involving change of direction or other movement patterns and motor performance to determine angle of inversion available with each of the test devices.

5. Use self digitizing points to increase accuracy.

6. Use more subjects.

7. Have the subjects wear shoes during the videotaped walking and running on the treadmill.

8. Apply the taping technique directly to the subjects' skin.

9. Use other brands of lace-up ankle stabilizers and semirigid orthotic devices. 


\section{REFERENCES}

Abdenour, T.E., Saville, W.A., White, R.C., \& Abdenour, M.A. (1979). The effect of ankle taping upon torque and range of motion. Athletic Training, 14, 227-228.

Amheim, D.D. (1989). Modern principles of athletic training, (7th ed.), St. Louis: Mirror/Mosby.

Bergfeld, J.A., Cox, J.S., Drez, D., Raemy, H., \& Weiker, G.G. (1986). Management of acute ankle sprains. Contemporary Orthopaedics, 13(3).

Booher, J.M., \& Thibodeau, G.A. (1989). Athletic injury assessment, (2nd ed.), St. Louis: Mirror/Mosby.

Bullard, R.H., Dawson, J., \& Arenson, D.J. (1979). Taping the athletic ankle. Journal of the American Podiatry Association, 69, 727-734.

Bunch, R.P., Bednarski, K., Holland, D., \& Macinanti, R. (1985). Ankle joint support: A comparison of reusable lace-on braces with taping and wrapping. The Phvsician and Sportsmedicine, $13(5), 59-62$.

Burdett, R.G., Borello-France, D., Blatchly, C., \& Potter, C. (1988). Gait comparison of subjects with hemiplegia walking unbraced, with ankle-foot orthosis, and with AirStirrup® brace. Physical Therapy, 68(8), 1197-1203.

Cavanagh, P.R., Rodgers, M.M., \& liboshi, A. (1987). Pressure distribution under symptom-free feet during barefoot standing. Foot and Ankle, $Z(5), 262-276$.

Cox, J.S., (1982). The diagnosis and management of ankle ligament injuries in the athlete. Athletic Training, 17, 192-196.

Cox, J.S., Inniss, R., Lee, E., \& Woodward, E.P. (1986). Ankle sprains. The Physician and Sportsmedicine, 14(2), 101-118. 
Daniels, L. \& Worthington, C. (1986). Muscle Testing: Techniques of Manual Examination, (5th ed.), Philadelphia: W.B. Saunders.

Davies, G.J. (1977). The ankle wrap: Variation from the traditional. Athletic Training, 12 , 194-197.

Emerick, C.E. (1979). Ankle taping: Prevention of injury or waste of time. Athletic Training, 14, 148-150; 188.

Felder, C.R., Mc Neely, J. (1978). Ankle taping: An alternative to the basketweave. Athletic Training, 13, 154-156.

Ferguson, A.B. (1973). The case against ankle taping. The Journal of Sports Medicine, \anuary/February, 46-47.

Fritschy, D., Junet, C., \& Bonvin, J.C. (1987). Functional treatment of severe ankle sprain. Journal of Traumatology in Sport, 4, 131-136.

Fumich, R.M., Ellison, A.E., Guerin, G.J., \& Grace, P.D. (1981). The measured effect of taping on combined foot and ankle motion before and after exercise. The American Journal of Sports Medicine, 2, 165-169.

Garrick, J.G. (1977). The frequency of injury, mechanism of injury, and epidemiology of ankle sprains. The American Journal of Sports Medicine, 5, 241-242.

Garrick, J.G., \& Requa, R.K. (1973). Role of external support in the prevention of ankle sprains. Medicine and Science in Sports and Exercise, 5, 200-203.

Gehlsen, G.M., Pearson, D., \& Bahamonde, R. (1991). Ankle joint strength, total work, and range of motion: Comparison between prophylactic devices. Athletic Training 26 , $62-65$.

Gehlsen, G.M., Pearson, D., \& Bahamonde, R. (1989). Subtalar joint movement during running on camber: Comparison between prophylactic devices. Manuscript submitted for publication. 
Glick, J.M., Gordon, R.B., \& Nishimoto, D. (1976). The prevention and treatment of ankle injuries. Athletic Training, 4, 6-7.

Gross, M.T., Bradshaw, M.K., Ventry, L.C., \& Weller, K.H. (1987). Comparison of support provided by ankle taping and semirigid orthosis. The Journal of Othopaedic and Sports Physical Therapy, 2, 33-39.

Hamill, J., Morin, G., Clarkson, P.M., \& Andres, R.O. (1988). Exercise moderation of foot function during walking with a re-usable semirigid ankle orthrosis. Clinical

Biomechanics, 3 , 153-158.

Hlavac, Harry F. (1977). The foot book: Advice for athletes, Mountain View, CA: World Publications.

Hoppenfeld, S. (1976). Physical examination of the spine and extremities, East Norwalk, CT: Appleton-Century-Crofts.

Hoshowsky, V.M. (1988). Chronic lateral ligament instability of the ankle. Orthopaedic Nursing, Z(3), 33-40.

Hughes, L.Y., \& Stetts, D.M. (1983). A comparison of ankle taping and semi-rigid support. The Physician and Sportsmedicine, 11(4), 99-103.

Kimura, I.F., Nawoczenski, D.A., Epler, M., \& Owen, M.G. (1987). Effect of the AirStirrup in controlling ankle inversion stress. The Journal of Orthopaedic and Sports Physical Therapy, 2(5), 190-193.

Laughman, R.K., Carr, T.A., Chao, E.Y., Youdus, J.W., \& Sim, F.H., (1980). Three dimensional kinematics of the taped ankle before and after exercise. The American Journal of Sports Medicine, 8, 425-431.

Libera, D. (1972). Ankle taping, wrapping, and injury prevention. Athletic Training, I, 73-75.

Magee, D.J. (1987). Orthopedic physical assessment. Philadelphia: W.B. Saunders. 
Malina, R.M., Plagnez, L.B., \& Rarick, G.L. (1963). Effects of exercise on the measureable supporting strength of cloth and tape ankle wraps. Research Quarterly, 34 , 158-165.

McCluskey, G.M., Blackbum, T.A., \& Lewis, T. (1976). Prevention of ankle sprains. The American Journal of Sports Medicine, 4, 151-157.

McIntyre, D.R., Smith, M.A., \& Denniston, N.L. (1983). The effectiveness of strapping technique during prolonged dynamic exercises. Athletic Training, 18, 52-55.

Metcalf, G.R., \& Denegar, C.R. (1983). A critical review of ankle taping. Athletic Training, 18, 121-122.

Moseley, H.F. (1965). Traumatic disorders of the ankle and foot. In J.H. Walton (Ed.), Clinical Symposia, 17(1). Summit, New Jersey: Ciba-Geigy Corporation.

Myburgh, K.H., Vaughn, C.L., \& Isaacs, S.K. (1984). The effects of ankle guards and taping on joint motion before and after a squash match. The American Journal of Sports Medicine, 12 , 441-446.

O' Donoghue, D.H. (1984). Treatment of injuries to athletes. (4th Ed), Philadelphia, PA: Saunders.

Perlman, M., Leveille, D., DeLeonibus, J., Hartman, R., Klein, J., Handleman, R., Schulz, E., \& Wertheimer, L. (1987). Inversion lateral ankle trauma: Differential diagnosis, review of the literature, and prospective study. Journal of Foot Surgery, $\underline{26}(2), 95-135$.

Raemy, H., \& Jakob, R.P. (1983). Functional treatment of fresh fibular ligament lesions using the Aircast $\circledast$ splint. Swiss Journal of Sportsmedicine, 31, 53-57.

Rarick, G.L., Bigley, G., Karst, R., \& Malina, R.M. (1962). The measureable support of the ankle joint by conventional methods of taping. The Journal of Bone and Joint Surgery, 44, 1183-1190. 
Rasch, P.J. (1989). Kinesiology and applied anatomy (7th Ed), Philadelphia, PA: Lea \& Febiger.

Robinson, J.R., Frederick, E.C., \& Cooper, L.B. (1986). Systematic ankle stabilization and the effect on performance. Medicine and Science in Sports and Exercise, 18, 625628.

Rovere, G.D., Clarke, T.J., Yates, C.S., \& Burley, K. (1988). Retrospective comparison of taping and ankle stabilizers in preventing ankle injuries. The American Journal of Sports Medicine, 16, 228-233.

Roy, S., \& Irvin, R. (1983). Sportsmedicine: Prevention, evaluation, management, and rehabilitation, Englewood Cliffs, NJ: Prentice-Hall.

Seitz, C.J., \& Goldfuss, A.J. (1984). The effects of taping and exercise on passive foot inversion and ankle plantarflexion. Athletic Training, 19, 178-182.

Simon, J.E. (1969). Study of comparative effectiveness of ankle wrapping on the prevention of injuries. Athletic Training, 4, 6-7.

Stover, C.N. (1979). A functional semirigid support system for ankle injuries. The Physician and Sportsmedicine, I(5), 71-78.

Stover, C.N. (1980). Air-stirrup management of ankle injuries in the athlete. The American Journal of Sports Medicine, $8,360-365$.

Stover, C.N. (1986). Functional sprain management of the ankle. Ambulatory Care, $6(11)$.

Stover, C.N., \& York, J.M. (1979). The Aircast/Airstimup system for graduated management of lower extremity injuries. A scientific exhibit paper, American Academy Of Orthopeadic Surgeons, San Francisco, CA.

Stover, C.N., DeBald, M. (1986), Guide to lateral ankle sprain management. Orthopaedic Nursing, 5(3), 34-39. 
Stuessi, E., Tiegermann, V., Gerber, H., Raemy, H., Stacoff, A. (1987). A

biomechanical study of the stabilization effect of the Aircast ankle brace. Biomechanics X-

A International Series on Biomechanics: Vol. 6A (pp. 159-164). Champaign, Il:

Human Kinetics Publishers.

Torg, J.S., Vegso, J.J., \& Torg, E. (1987). Rehabilitation of athletic injuries: An atlas of therapeutic exercise, Chicago: Year Book Medical Publishers, Inc.

Vaes, P., DeBoeck, H., Handelberg, F., \& Opdecam, P. (1985). Comparative radiological study of the influence of ankle joint strapping and taping on ankle stability. The Joumal of Qrthopaedic and Sports Physical Therapy, 7, 110-114.

VanDam, R.L., \& Ruhling, R.O. (1975). Tape composition and performance. Athletic Training, 10, 214-216.

Walsh, W.M., \& Blackburn, T. (1977). Prevention of ankle sprains. The American Journal of Sports Medicine, 5(6), 243-245.

Walters, F.E., Elledge, J.R., Tolson, H., \& Pankey, R.B. (1988). The effects of selected ankle prophylaxis on inversion range of motion. Manuscript submitted for publication.

Wells, J. (1969). The incidence of knee injuries in relation to ankle taping. Athletic Training, 4, 10-13. 


\title{
APPENDIX A \\ AGREEMENT TO PARTICIPATE IN RESEARCH SAN JOSE STATE UNIVERSITY
}

\author{
RESPONSBLE INVESTIGATOR: Natalie Martin, Graduate Student
}

TITLE OF PROTOCOL: The Comparative Effectiveness of Ankle Prophylactic Devices in Limiting Inversion Before and After Vigorous Exercise.

I have been asked to participate in a research study that is investigating the effectiveness of several ankle supports in limiting excess ankle range of motion, and thus prevent ankle sprains. The results of this study should further understanding of the efficacy of the routine practice of adhesive athletic taping or bracing uninjured ankles for athletic participation.

\section{I understand that}

1) I will be asked to complete a control condition without being taped or braced, have my ankle taped or braced, complete an exercise session, and be videotaped while walking ( $4 \mathrm{mph}$ ) and running ( $9 \mathrm{mph}$ ) on a $6 \%$ grade laterally tilted treadmill. The first data session requires approximately 60 minutes; the three successive data collection sessions will also take approximately 60 minutes for a total time commitment of approximately 4 hours. Testing will occur four times a week for one week. All activity will occur in SPX 208 and SPX 75. I also understand that I will be asked to complete a written questionaire following the last test session.

2) the risks of this study are minimal, but include: muscular soreness associated with the training sessions, skin irritation from the adhesive tape and/or adhesive spray, and a treadmill accident. The treadmill is tilted at an angle to approximate a city street, and any risk of injury is similar to that associated with jogging or running on a city street.

3) the possible benefits of this study to me are the further development of the base of scientific knowledge in the area of ankle prophylaxis.

4) the results from this study may be published, but any information from this study that can be identified with me will remain confidential and will be disclosed only with my permission or as required by law.

5) any question about my participation in this study will be answered by Natalie Martin at (408) 924-3030. Complaints about the procedures may be presented to Rod A. Harter, Ph.D. (Thesis advisor) at (408) 924-3015. For questions or complaints about research subject's rights, or in the event of research-related injury, contact Serena Stanford, Ph.D. (Associate Academic Vice President for Graduate Studies \& Research) at (408) 924-2480.

6) my consent is given voluntarily without being coerced; I may refuse to participate in this study or in any part of this study, and I may withdraw at any time, without prejudice to my relations with SJSU. 
7) I have received a copy of this consent form for my file.

I HAVE MADE A DECISION WHETHER OR NOT TO PARTICIPATE. MY SIGNATURE INDICATES THAT I HAVE READ THE INFORMATION PROVIDED ABOVE AND THAT I HAVE DECIDED TO PARTICIPATE.

$\overline{\text { DATE }}$

SUBJECT'S SIGNATURE

PRINT LAST NAME

INVESTIGATOR'S SIGNATURE 
APPENDIX B

RATINGS OF PROPHYLACTIC DEVICES

Subject \#:

Athletic Tape:
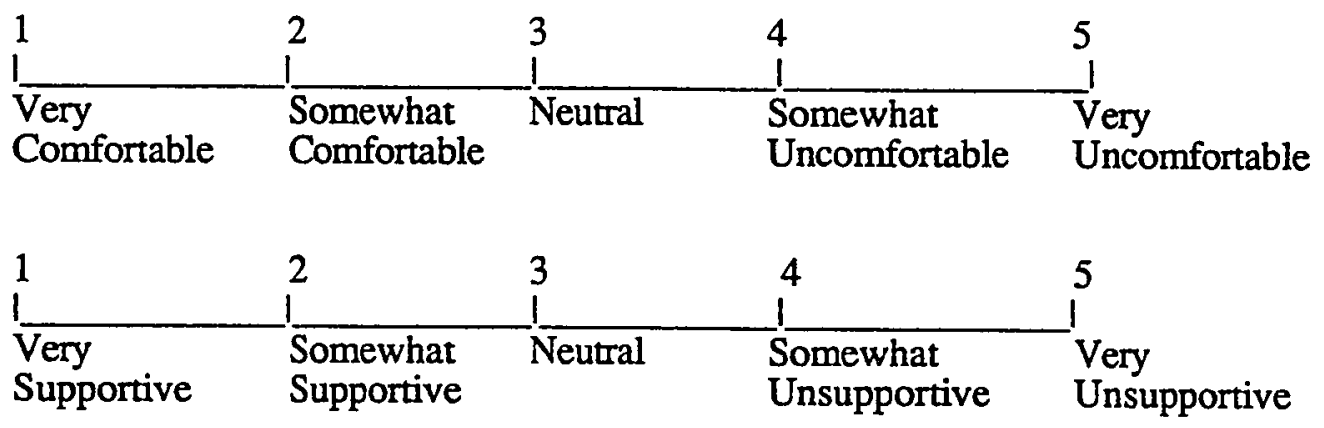

\section{Comments:}

Lace-up Ankle Stabilizer:

\begin{tabular}{|c|c|c|c|c|}
\hline 1 & 2 & 3 & $\begin{array}{l}4 \\
1\end{array}$ & 5 \\
\hline $\begin{array}{l}\text { Very } \\
\text { Comfortable }\end{array}$ & $\begin{array}{l}\text { Somewhat } \\
\text { Comfortable }\end{array}$ & Neutral & $\begin{array}{l}\text { Somewhat } \\
\text { Uncomfortable }\end{array}$ & $\begin{array}{l}\text { Very } \\
\text { Uncomfortable }\end{array}$ \\
\hline
\end{tabular}

$\begin{array}{lllll}1 & 2 & 3 & 4 & 5 \\ 1 & \mid & 1 & 1 & 1 \\ \text { Very } & \text { Somewhat } & \text { Neutral } & \text { Somewhat } & \text { Very } \\ \text { Supportive } & \text { Supportive } & & \text { Unsupportive }\end{array}$

Comments: 
Semi-Rigid Orthosis:

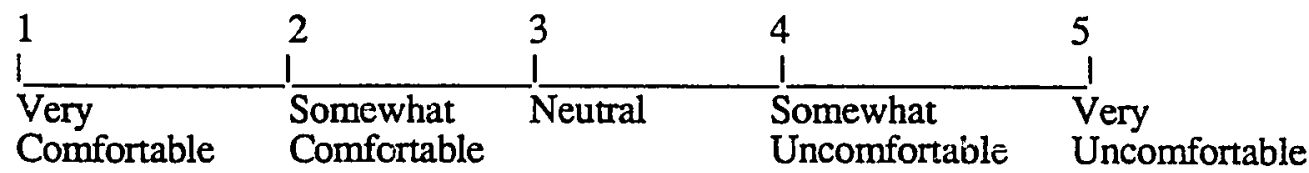

\begin{tabular}{|c|c|c|c|c|}
\hline 1 & 2 & 3 & 4 & 5 \\
\hline $\begin{array}{l}\text { Very } \\
\text { Supportive }\end{array}$ & $\begin{array}{l}\text { Somewhat } \\
\text { Supportive }\end{array}$ & Neutral & $\begin{array}{l}\text { Somewhat } \\
\text { Unsupportive }\end{array}$ & Unsupportive \\
\hline
\end{tabular}

Comments: 
Appendix C

Data Recording Sheet

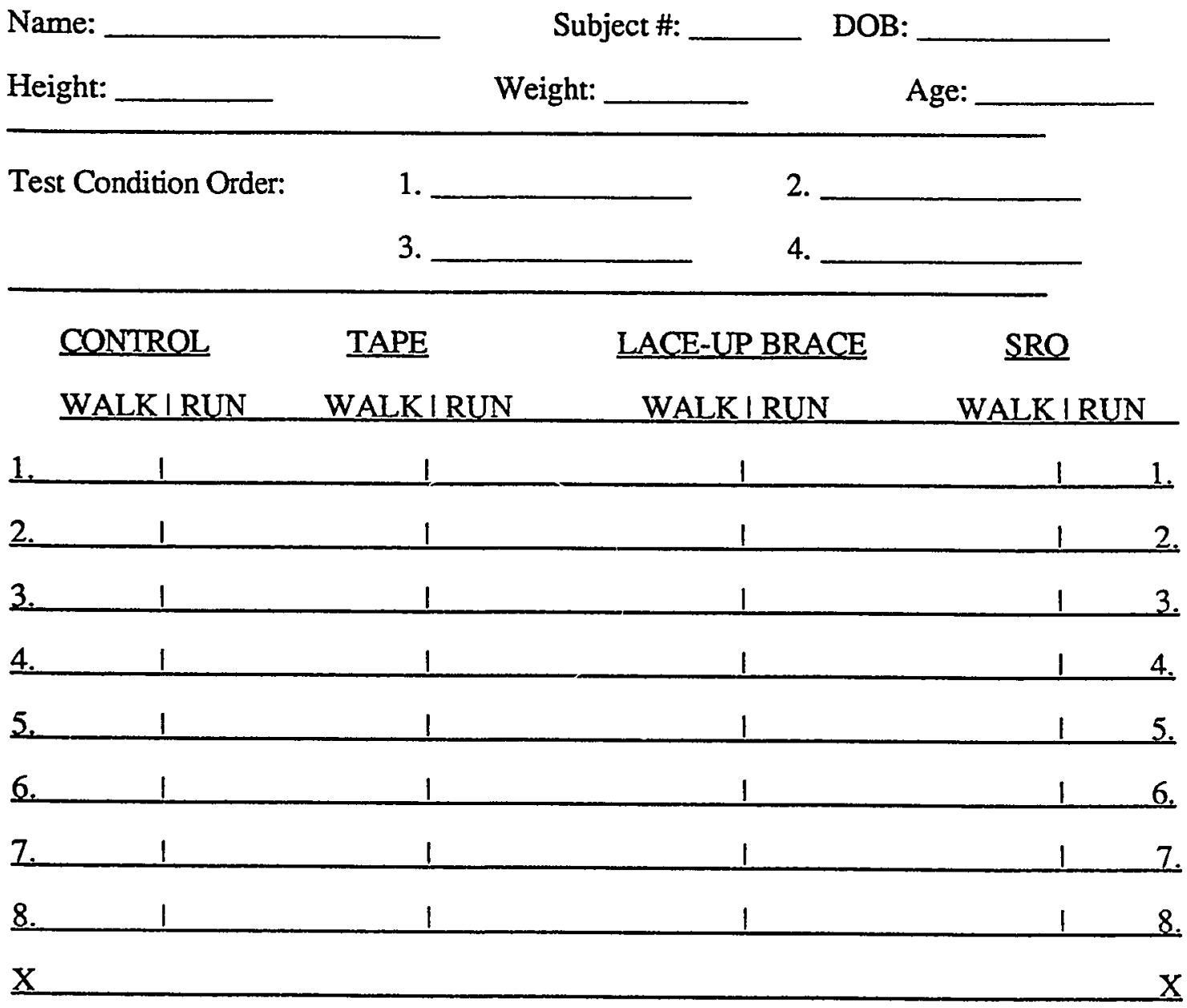

Passive Inversion ROM:

Active Inversion ROM: PRE-TEST

POST-TEST

Control

Control

Tape

Tape

Lace-up

Lace-up

SRO SRO 


\section{APPENDIX D}

RAW DATA SCORES

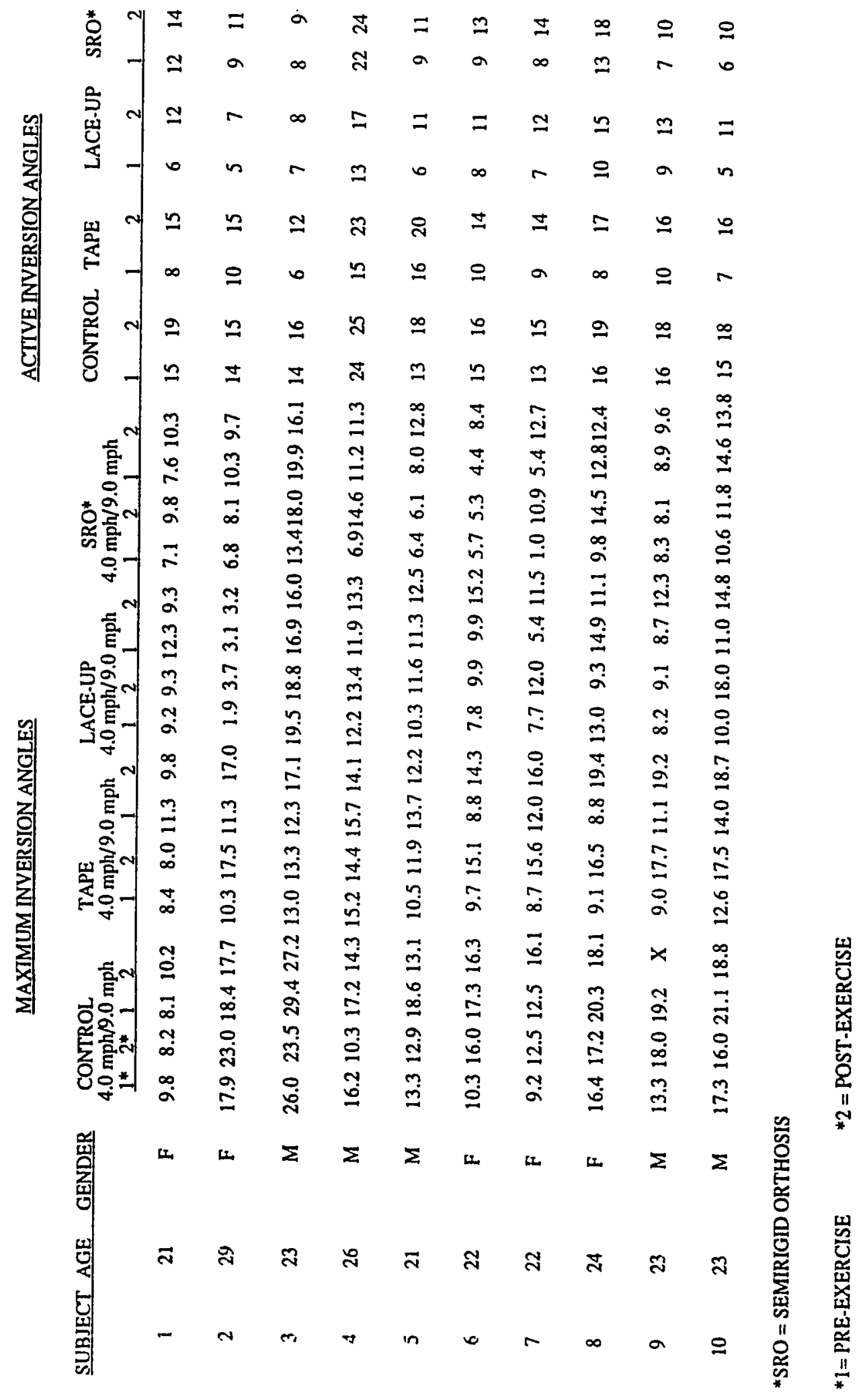

